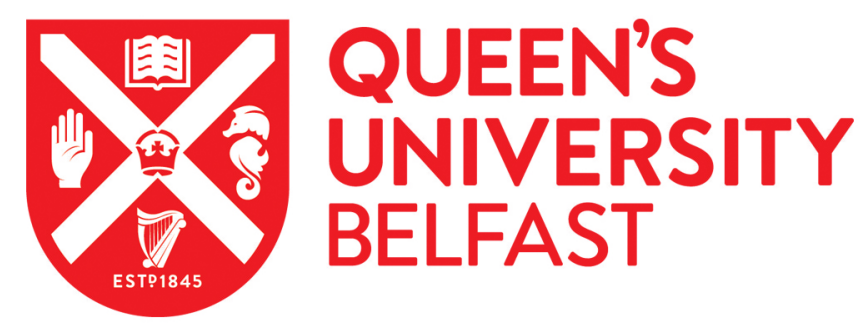

\title{
A Comparative Study between Hot-Melt Extrusion and Spray-Drying for the Manufacture of Anti-Hypertension Compatible Monolithic Fixed-Dose Combination Products
}

Kelleher, J. F., Gilvary, G. C., Madi, A. M., Jones, D. S., Li, S., Tian, Y., Almajaan, A., Senta Loys, Z., Andrews, G. P., \& Healy, A. M. (2018). A Comparative Study between Hot-Melt Extrusion and Spray-Drying for the Manufacture of Anti-Hypertension Compatible Monolithic Fixed-Dose Combination Products. International Journal of Pharmaceutics. https://doi.org/10.1016/j.ijpharm.2018.05.008

Published in:

International Journal of Pharmaceutics

Document Version:

Peer reviewed version

Queen's University Belfast - Research Portal:

Link to publication record in Queen's University Belfast Research Portal

\section{Publisher rights}

Copyright 2018 Elsevier.

This manuscript is distributed under a Creative Commons Attribution-NonCommercial-NoDerivs License

(https://creativecommons.org/licenses/by-nc-nd/4.0/), which permits distribution and reproduction for non-commercial purposes, provided the author and source are cited.

\section{General rights}

Copyright for the publications made accessible via the Queen's University Belfast Research Portal is retained by the author(s) and / or other copyright owners and it is a condition of accessing these publications that users recognise and abide by the legal requirements associated with these rights.

\section{Take down policy}

The Research Portal is Queen's institutional repository that provides access to Queen's research output. Every effort has been made to ensure that content in the Research Portal does not infringe any person's rights, or applicable UK laws. If you discover content in the

Research Portal that you believe breaches copyright or violates any law, please contact openaccess@qub.ac.uk. 


\section{Accepted Manuscript}

A Comparative Study between Hot-Melt Extrusion and Spray-Drying for the Manufacture of Anti-Hypertension Compatible Monolithic Fixed-Dose Combination Products

J.F. Kelleher, G.C. Gilvary, A.M. Madi, D.S. Jones, S. Li, Y. Tian, A. Almajaan, Z. Senta-Loys, G.P. Andrews, A.M. Healy

PII: S0378-5173(18)30301-6

DOI: https://doi.org/10.1016/j.ijpharm.2018.05.008

Reference: $\quad$ IJP 17479

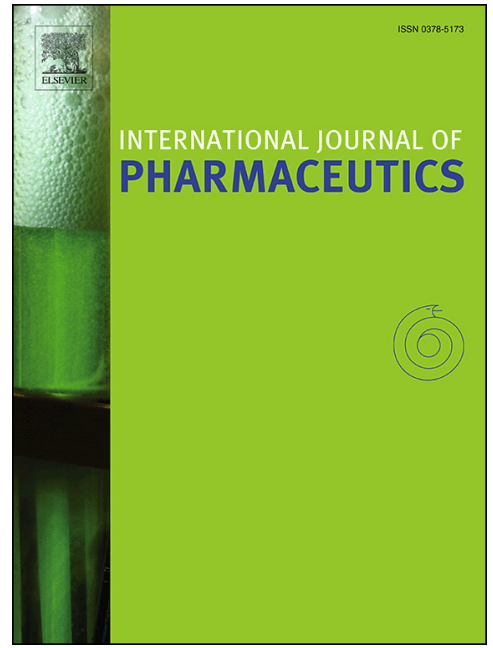

To appear in:

\section{International Journal of Pharmaceutics}

Received Date: $\quad 8$ March 2018

Revised Date: $\quad 30$ April 2018

Accepted Date: $\quad 2$ May 2018

Please cite this article as: J.F. Kelleher, G.C. Gilvary, A.M. Madi, D.S. Jones, S. Li, Y. Tian, A. Almajaan, Z. SentaLoys, G.P. Andrews, A.M. Healy, A Comparative Study between Hot-Melt Extrusion and Spray-Drying for the Manufacture of Anti-Hypertension Compatible Monolithic Fixed-Dose Combination Products, International Journal of Pharmaceutics (2018), doi: https://doi.org/10.1016/j.ijpharm.2018.05.008

This is a PDF file of an unedited manuscript that has been accepted for publication. As a service to our customers we are providing this early version of the manuscript. The manuscript will undergo copyediting, typesetting, and review of the resulting proof before it is published in its final form. Please note that during the production process errors may be discovered which could affect the content, and all legal disclaimers that apply to the journal pertain. 
A Comparative Study between Hot-Melt Extrusion and Spray-Drying for the Manufacture of Anti-Hypertension Compatible Monolithic Fixed-Dose Combination Products

J. F. Kelleher ${ }^{1}$, G. C. Gilvary ${ }^{2}$, A. M. Madi ${ }^{1}$, D. S. Jones ${ }^{2}$, S. Li ${ }^{2}$, Y. Tian ${ }^{2}$, A. Almajaan ${ }^{2}$, Z. Senta-Loys ${ }^{2}$, G. P. Andrews ${ }^{2}$, A. M. Healy ${ }^{1, *}$

Affiliation

${ }^{1}$ School of Pharmacy and Pharmaceutical Sciences, Trinity College Dublin, Dublin, Ireland

${ }^{2}$ School of Pharmacy, Queen's University of Belfast, Belfast, Northern Ireland

*To whom correspondence should be addressed to:

Anne Marie Healy

Tel: +35318961444

Email: healyam@tcd.ie 
Abstract

The purpose of this work was to investigate the application of different advanced continuous processing techniques (hot melt extrusion and spray drying) to the production of fixed-dose combination (FDC) monolithic systems comprising of hydrochlorothiazide and ramipril for the treatment of hypertension. Identical FDC formulations were manufactured by the two different methods and were characterised using powder x-ray diffraction (PXRD) and modulated differential scanning calorimetry (mDSC). Drug dissolution rates were investigated using a Wood's apparatus, while physical stability was assessed on storage under controlled temperature and humidity conditions. Interestingly both drugs were transformed into their amorphous forms when spray dried, however, hydrochlorothiazide was determined, by PXRD, to be partially crystalline when hot melt extruded with either polymer carrier (Kollidon $^{\circledR}$ VA 64 or Soluplus ${ }^{\circledR}$ ). Hot melt extrusion was found to result in significant degradation of ramipril, however, this could be mitigated by the inclusion of the plasticizer, polyethylene glycol 3350, in the formulation and appropriate adjustment of processing temperature. The results of intrinsic dissolution rate studies showed that hot-melt extruded samples were found to release both drugs faster than identical formulations produced via spray drying. However, the differences were attributable to the surface roughness of the compressed discs in the Wood's apparatus, rather than solid state differences between samples. After a 60-day stability study spray dried samples exhibited a greater physical stability than the equivalent hot melt extruded samples.

Key words: Hot melt extrusion, spray drying, fixed dose combinations, continuous manufacture, amorphous solid dispersions. 


\section{Introduction}

A fixed dose combination (FDC) product is defined as a combination product that includes two or more active pharmaceutical ingredients (APIs) combined in a single dosage form, which is manufactured and distributed in fixed doses (Gautam and Saha, 2008). FDCs offer many advantages for patients on multiple drugs to treat the same condition, most notably, reducing the pill burden and as a result, increasing patient compliance (Farrell et al., 2013). The ever-increasing role FDC products play in healthcare is evident from the increasing numbers available on the market. FDC approvals by the Food and Drug Administration (FDA) in the United States increased from 12 in the 1980s to 59 in the 2000s (Hao et al., 2015). The World Health Organisation (WHO) has also increased the number of FDC products on their essential medication list, with 32 FDCs on the March 2017 (World Health Organization, 2017) published list, which is nearly double the number of FDC products that were on the list in 2002.

Traditionally, batch manufacturing is utilized to produce pharmaceutical products, including FDCs. In this process, going from one step to the next, materials are tested off-line and stored before being transferred to the next processing step. In continuous manufacturing processes, such as spray drying (SD) (Gursch et al., 2015) and hot melt extrusion (HME) (Gursch et al., 2015), there is a continuous feed input and product output in a one-step process. Inline process analytical techniques (PAT) and quality by design $(\mathrm{QbD})$ ensure desired parameters are maintained throughout the continuous process, allowing manufacture to continue up to 24 hours per day if required (Lee, 2015). While continuous manufacturing processes are relatively new in the pharmaceutical arena, more companies are moving towards continuous manufacturing as it promises to reduce costs while also increasing the quality, agility and flexibility of products (McKenzie et al., 2006).

HME and SD are two of most common processing techniques used in continuous manufacturing (Agrawal et al., 2016) and can be used to produce solid dispersions. Often one 
method of preparation for solid dispersions is arbitrarily chosen and then formulation scientists modify the formulation until the desired characteristics are achieved (Agrawal et al., 2016). However, solid dispersions prepared by different techniques can often display differences in their physicochemical properties (Agrawal et al., 2016; Riekes et al., 2014; Sethia and Squillante, 2004). Therefore, during early stage development of a formulation, it may be important to understand the influence of the processing technique on the desired formulation.

SD and HME are techniques that may be employed to produce FDCs, with both techniques having their own associated advantages and disadvantages. Thermal (and mechanical) energy input during the extrusion process is normally supplied via heat conduction from barrel heating zones and the friction of the melt against the screw elements and interior wall of the extruder barrel (Huang et al., 2017). It is because of this heat conduction that degradation of thermolabile compounds can arise. Despite this drawback, HME has had a well-documented history as a continuous, solvent-free, robust, quick and cost-effective pharmaceutical manufacturing process for the production of a wide variety of dosage forms (Patil et al., 2015). While the application of HME to thermolabile drugs remains challenging and is one of its main limitations, heat sensitive drugs have been successfully processed using this technique (Repka et al., 1999). However, as a result of this possible thermal degradation, SD may be more useful for thermolabile materials, as it can be used to process solutions or suspensions (Aulton and Taylor, 2013) at relatively low processing temperatures, due to the availability of a wide range of volatile solvents. While the wide range of solvents is advantageous for processing materials at low temperatures, one of the main disadvantages of SD is the use of organic solvents in the process. The pharmaceutical industry in recent years has tried to move away from the use of organic solvents due to the harmful effects they can have on the environment, but also due to the effects residual solvents may have on manufactured products produced (Dunn et al., 2010) 
Angiotensin converting enzyme (ACE) inhibitors and thiazide diuretics in fixed dose combination products have been shown to reduce blood pressure (BP) more substantially than with individual therapy of the drugs alone (Ambrosioni et al., 1987; Brown et al., 1990; Chrysant, 1994). Hydrochlorothiazide (HCTZ), a thiazide diuretic (British Pharmacopoeia, 2018a), and ramipril (RAM), an ACE inhibitor (British Pharmacopoeia, 2018b), are both recommended for the treatment of hypertension (HPT) (World Health Organization, 2016). When dosage forms containing RAM in association with HCTZ are used, there is a significantly greater reduction in BP than with individual monotherapies at the same dosages (Scholze et al., 1993), probably due to the additive effects of both drugs. While the British Pharmacopeia states that HCTZ is very slightly soluble in water (British Pharmacopoeia, 2018a) and RAM is sparingly soluble in water (British Pharmacopoeia, 2018b), respectively, the Biopharmaceutics Classification System (BCS), classifies a substance to be highly soluble when the highest dose strength is soluble in less than $250 \mathrm{ml}$ water over the $\mathrm{pH}$ range of 1 to 7.5 at $37{ }^{\circ} \mathrm{C}$ (Lindenberg et al., 2004; Polli et al., 2004). While some authors have referred to HCTZ as a BCS class IV drug (high solubility, low permeability) (Ghadi and Dand, 2017; Löbenberg and Amidon, 2000; Sanphui et al., 2015), HCTZ, which has a p $K_{\mathrm{a}}$ value of 7.9 (O'Neill, 2013) has been reported to have a solubility ranging from $60.8 \mathrm{mg}$ to $103 \mathrm{mg}$ per $100 \mathrm{ml}$ within the $\mathrm{pH}$ range 1.0 to 7.4 (Blatnik et al., 2015). As the maximum daily dose of HCTZ is $100 \mathrm{mg}$ (Brayfield, 2014), HCTZ may be considered highly soluble according to the BCS system, as the maximum dose dissolves in less than $250 \mathrm{ml}$ water over the stated $\mathrm{pH}$ range, and it may thus be classed as a BCS class III (high solubility, low permeability) drug compound (Klein and Shah, 2008; Yu et al., 2004; Zaid et al., 2016). RAM has a $\mathrm{p} K_{\mathrm{a}}$ value of 3.17 (O’Neill, 2013). The maximum daily dose of RAM is $10 \mathrm{mg}$ (Brayfield, 2014) and, with a sparingly soluble (British Pharmacopoeia, 2018b) solubility in water, RAM is classified as a BCS class I (high solubility, high permeability) compound (Ramirez et al., 2010; Zaid et al., 2016). SD (Tajber et al., 2005) and HME (De Jaeghere et 
al., 2015; Dierickx et al., 2012; Vynckier et al., 2015, 2014) techniques have been previously successfully used to process HCTZ alone. RAM is thermally degraded at a relatively low temperature (upon melting, $117^{\circ} \mathrm{C}$ ). This therefore becomes a formulation challenge due to the high temperatures typically used in HME.

The literature contains many examples of research conducted to gain an understanding of the effect of the manufacturing technique on the physicochemical properties of solid dispersions containing a single API (Agrawal et al., 2016; Badens et al., 2009; Guns et al., 2011; Riekes et al., 2014; Sethia and Squillante, 2004). There is, however, a lack of discussion in the literature of the influence of different continuous manufacturing processes (such as SD and HME) on the solid state and performance characteristics of systems containing more than one API (i.e. FDCs).

The main objective of the current work is to produce FDCs for the treatment of HPT using continuous manufacturing techniques and to investigate how different manufacturing techniques affect physicochemical properties. We also aim to understand how these properties can affect manufacturability, product performance and physical stability. 


\section{Materials and Methods}

\subsection{Materials}

Ramipril (RAM) (Kemprotec, Carnforth, England) and hydrochlorothiazide (HCTZ) (Alfa Aesar, Heysham, England) were used as active pharmaceutical ingredients throughout this study. Vinylpyrrolidone-vinyl acetate co-polymer (Kollidon ${ }^{\circledR}$ VA 64, BASF, Ludwigshafen, Germany) and polyvinylcaprolactam - polyvinyl acetate - polyethylene glycol graft copolymer (Soluplus ${ }^{\circledR}$, ASF, Ludwigshafen, Germany) were studied as immediate-release polymers throughout this investigation. In addition, polyethylene glycol (PEG 3350 g/mol., Fagron, Waregem, Belgium) was used as a plasticizer. Solvents used for dissolving the compounds for the spray drying process were ethanol 99.5\% (v/v) (Corcoran Chemicals Ltd., Dublin, Ireland) and deionised water, which was obtained using an Elix 3 connected to a Synergy UV system (Millipore, UK). All other chemicals were obtained from Sigma-Aldrich (Dorset, UK) and were of analytical grade or equivalent and were used without any further treatment.

\subsection{Methods}

\subsubsection{Manufacture of Extrudates}

Polymer/ plasticizer and drugs were premixed using a mortar and pestle for 5 minutes. HME was performed using a co-rotating, fully intermeshing twin-screw extruder (Microlab, Rondol Technology Ltd, France). The extruder die (Rondol Technology Ltd, France) was $2 \mathrm{~mm}$ in diameter, and was connected to the end of the barrel. All heating zones were varied depending on the formulation (Table 3).

The premixes were fed into the extruder using a twin-screw powder feeder (Rondol Technology Ltd, France). After cooling, the cylindrical extrudates were manually cut using a sterile scalpel into pellets so that they could fit into the grinding jar for milling. HME samples 
were pulverised using a cryogenic ball-mill (Retsch Cryomill, Haan, Germany) for 3 cycles consisting of 5 minutes of grinding $(30 \mathrm{~Hz})$ followed by a 2-minute break before being physicochemically analysed. The milling was conducted under liquid nitrogen cooling conditions. The grinding jar material was composed of stainless steel and had a volume of 25 $\mathrm{ml}$. Three stainless steel ball bearings with a diameter of $10 \mathrm{~mm}$ were used to pulverise the HME extrudates into a fine powder.

\subsubsection{Preparation of the Spray-Dried (SD) systems}

Spray-dried systems were prepared using a Buchi B-290 Mini Spray Dryer (BÜCHI Labortechnik AG, Flawil, Switzerland). A two-fluid atomizer with a $0.7 \mathrm{~mm}$ nozzle tip and a $1.5 \mathrm{~mm}$ diameter nozzle screw cap were used. Formulations of drug and/or polymer/polymers were dissolved in $200 \mathrm{ml}$ of premixed solvent with a composition of $95 \%$ (v/v) ethanol, 5\% (v/v) deionised water. The inlet temperature, airflow, aspirator and feed rates at which the spray dryer was operated were kept at $78{ }^{\circ} \mathrm{C}, 660 \mathrm{Nl} / \mathrm{h}, 100 \%$ and $20 \%$, respectively. The outlet temperature remained between $45{ }^{\circ} \mathrm{C}-49^{\circ} \mathrm{C}$. The solution concentrations were kept constant at $5 \%(\mathrm{w} / \mathrm{v})$ for all formulations.

\subsubsection{Thermogravimetric analysis (TGA)}

Thermogravimetric analysis studies were conducted using a TGA Q50 (TA Instruments, Leatherhead, UK) to evaluate the onset of degradation of each of the individual ingredients. Samples (5-10 mg) were analysed in open aluminium pans (Perkin Elmer, Shelton, USA) using a linear heating rate of $10{ }^{\circ} \mathrm{C} / \mathrm{min}$ from $0-300{ }^{\circ} \mathrm{C}$. HME samples were pulverised using a cryogenic ball-mill before filling into the aluminium pans. The HME samples were pulverised into a powder to enable a direct comparison to the powder samples produced by SD. TGA data was analysed using Universal Analysis software (TA Instruments, Leatherhead, UK). Analysis was performed in triplicate. 


\subsubsection{Differential Scanning Calorimetry (DSC)}

The thermal behaviour of materials was analysed using a differential scanning calorimeter (Q200, TA Instruments, Leatherhead, UK). Nitrogen was used as the purge gas (60 $\mathrm{ml} / \mathrm{min})$. Calibration was performed with an indium standard. Samples $(5-10 \mathrm{mg})$ were analysed in crimped standard aluminium pans with a heating rate of $10^{\circ} \mathrm{C} / \mathrm{min}$. DSC data was analysed using Universal Analysis software (TA Instruments). Melting temperatures of drugs were determined and reported as peak temperature. The glass transition temperatures were defined as the midpoint of the transition. Analysis was performed in triplicate.

\subsubsection{Modulated Differential Scanning Calorimetry (mDSC)}

Samples were directly filled into standard aluminium pans (3-8 mg) (TA Instruments, Leatherhead, UK) and analysed using mDSC (Q200, TA Instruments, Leatherhead, UK). Nitrogen was used a purge gas $(60 \mathrm{ml} / \mathrm{min})$. A heating rate of $5^{\circ} \mathrm{C} / \mathrm{min}$, a modulation amplitude of $0.53{ }^{\circ} \mathrm{C}$ and a period of 40 seconds were used. Runs were halted at $260{ }^{\circ} \mathrm{C}$ as products started to completely degrade above this temperature. Analysis was performed in triplicate.

\subsubsection{Powder X-Ray Diffraction (PXRD)}

The crystallinity of the drugs in physical mixtures, extrudates and SD samples were analysed using (wide angle) PXRD. HME samples were pulverised using a cryogenic ball-mill before analysis. PXRD was performed on a Mini-Flex II (Rigaku ${ }^{\mathrm{TM}}$ Corporation, Japan) with $\mathrm{Cu} \mathrm{K}$ radiation $(30 \mathrm{kV})$ in the angular range (2 ) varying from 5-40 ${ }^{\circ}$ using a step scan mode with a step width of $0.02^{\circ}$ and a counting time of $2 \mathrm{~s} /$ step. Scans were performed in triplicate at room temperature. 


\subsubsection{Attenuated total reflectance Fourier transform infrared spectroscopy (ATR-FTIR)}

Infrared spectra were recorded on a PerkinElmer Spectrum 1 FT-IR Spectrometer equipped with a UATR and a ZnSe crystal accessory. Each spectrum was scanned in the range of 650$4000 \bullet \mathrm{cm}^{-1}$ with a resolution of $4 \cdot \mathrm{cm}^{-1}$. Data were evaluated using Spectrum v 5.0.1. software. Four scans of each sample were taken. The crystalline materials in the formulations were converted to their amorphous component counterparts by melt quenching (heating on a hotplate and subsequently dipping into liquid nitrogen) and these were mixed in the desired proportions using a pestle and mortar to obtain amorphous physical mixtures which were then subjected to FT-IR.

\subsubsection{Scanning Electron Microscopy (SEM)}

SEM was conducted on both particles and surfaces of compacts compressed in the Wood's apparatus (for dissolution testing). The surface images of the samples were captured at various magnifications by SEM using a Zeiss Supra Variable Pressure Field Emission Scanning Electron Microscope (Zeiss, Oberkochen, Germany) equipped with a secondary electron detector at $5 \mathrm{kV}$. Powder samples were glued onto carbon tabs mounted on to aluminium pin stubs and sputter-coated with gold under vacuum prior to analysis. Powder compacts were glued onto aluminium stubs using carbon cement and sputter-coated with gold under vacuum prior to analysis.

\subsubsection{Particle Size Analysis (PSA)}

Particle size measurements were performed by laser diffraction using a Malvern Mastersizer 2000 particle sizer (Malvern Instruments Ltd, Worchester, UK) with Scirocco 2000 accessory. The dispersive air pressure used was 2.5 bar. Samples were run at a vibration feed rate of $50 \%$. The particle size reported is the median diameter $\mathrm{d}(0.5)$. The $\mathrm{d}(0.5)$ is the diameter where $50 \%$ of the cumulative distribution is above and $50 \%$ is below this size. The 
values presented are the average of at least three determinations. Mastersizer 2000 software (Version 5.61) was used for the analysis of the particle size.

\subsubsection{Intrinsic drug dissolution}

The intrinsic dissolution rate of manufactured formulations was determined using a Wood's apparatus (Quality Lab Accessories, Telford, PA, USA.). $200 \mathrm{mg}$ of each formulation (equivalent to $10 \mathrm{mg}$ RAM and $25 \mathrm{mg} \mathrm{HCTZ)} \mathrm{was} \mathrm{weighed} \mathrm{and} \mathrm{compressed} \mathrm{in} \mathrm{the} 8 \mathrm{~mm}$ punch and die set of the Wood's apparatus, at a pressure of 3 tonnes for 1 minute using a hydraulic press (Perkin Elmer, Shelton, USA). The Wood's apparatus was then attached to a Sotax AT-7 dissolution bath (Sotax, Wallbrunnstraße, Germany). The dissolution study was carried out using $0.1 \mathrm{M} \mathrm{HCl}$ as the dissolution medium (volume: $500 \mathrm{ml}$, temperature: $37^{\circ} \mathrm{C}$, $\mathrm{pH}:$ 1.2) and a rotational speed of $100 \mathrm{rpm} .5 \mathrm{ml}$ aliquots were withdrawn and were replaced with fresh media at the pre-determined time intervals. Samples were filtered through PTFE hydrophilic $0.45 \mu \mathrm{m}$ filters (Fisher Scientific Ireland Ltd., Dublin, Ireland) and were analysed for drug content by HPLC (Agilent 1200 Infinity Series, Agilent Technologies, Cheadle, UK) using a gradient HPLC method. The linearity range was between $5-250 \mu \mathrm{g} / \mathrm{ml}$ for hydrochlorothiazide and $5-250 \mu \mathrm{g} / \mathrm{ml}$ for ramipril with regression coefficient $\left(\mathrm{r}^{2}\right)$ of 0.999 and 0.998 respectfully. The HPLC mobile phases consisted of a $0.1 \mathrm{M}$ sodium perchlorate solution adjusted to $\mathrm{pH} 2.5$ (mobile phase A) and acetonitrile (mobile phase B). Details of the gradient elution used are shown in Table 1 . Separation was performed on a Kinetex ${ }^{\circledR} \mathrm{C} 18$ column (150 mm length, diameter $4.6 \mathrm{~mm}$, particle size $5 \mu \mathrm{m}$ ) with UV detection at $210 \mathrm{~nm}$.

The dissolution study was terminated after $120 \mathrm{~min}$. The intrinsic dissolution release rate was determined from the slope of the dissolution time profiles over the first 30 minutes. Analysis was performed in triplicate.

\subsubsection{Surface topography}


The surface topography of compressed discs was assessed using a Filmetrics Profilm3D profilometer (San Diego, USA). Calibration was performed by using a VLSI surface topography reference step height standard with a height of $1.8 \mu \mathrm{m}$. The profilometer achieves measurements using vertical scanning interferometry (VSI) combined with high-accuracy phase shifting interferometry (PSI) to provide access to surface topography from subnanometre to millimetre scale. The profilometer was used to measure the surface roughness of the compressed discs and calculate $\mathrm{Ra}$, the roughness average of a surface's measured microscopic peaks and valleys. Area scans of the disc surfaces were made. The transverse lengths were $1.92 \mathrm{~mm}$ in the $\mathrm{X}$ direction and $1.68 \mathrm{~mm}$ in the $\mathrm{Y}$ direction. The profilometer used has a spot size diameter of $0.88 \mu \mathrm{m}$. Roughness data was calculated by SPIP V5.1.5.0 software. Samples were sputter-coated with gold under vacuum prior to analysis. Scans and analysis were performed in triplicate. Statistical analysis was conducted using Minitab® 16 software. A two-sample t-test was carried out comparing the surface roughness of the SD formulation compressed discs with that of the cryomilled HME formulation compressed discs.

\subsubsection{Stability Studies}

Formulations produced by SD and HME methods were placed on short-term stability at two relative humidity $(\mathrm{RH})$ conditions $\left(25{ }^{\circ} \mathrm{C} / 75 \% \mathrm{RH}\right.$, and $\left.25{ }^{\circ} \mathrm{C} /<10 \% \mathrm{RH}\right)$ for 60 days. Sample storage conditions were monitored using the Amebis Stability Testing and Monitoring System (Amebis Ltd., Ireland). A suitable amount of test material was transferred to Amebis sample chambers containing a pre-prepared saturated salt solution to regulate the relative humidity. The sample chamber containing the test material and saturated salt solution was subsequently transferred to a temperature-controlled cabinet at the specified temperature. The integrated temperature and humidity sensor within the Amebis system wirelessly transmitted and logged data regarding the environmental conditions within each test chamber 
to the Amebis Control Software (Amebis Ltd., Ireland) at 30-minute intervals. The Amebis system allowed for remote monitoring of both temperature and relative humidity conditions without the need to remove the chamber for data retrieval/monitoring. Samples were taken and analysed periodically by PXRD, mDSC and HPLC over the course of 60 days to test for amorphous/crystalline nature and drug content.

\subsubsection{Assay of Drug Content}

$50 \mathrm{mg}$ of each formulation was accurately weighed using a microbalance (Mettler-Toledo, Leicester, UK), added to a $50 \mathrm{ml}$ volumetric flask and made up to the mark with $0.1 \mathrm{M} \mathrm{HCl}$ solution. The solution was sonicated for $10 \mathrm{~min}$ to ensure the formulation was fully dissolved before being analysed by HPLC (as described above). Drug content was calculated by determining the area under the curve and comparing to area under the curve of standards of known concentration. The range of the calibration curve for HCTZ was between $5 \mu \mathrm{g} / \mathrm{ml}$ and $250 \mu \mathrm{g} / \mathrm{ml}$. The range of the calibration curve for RAM was between $5 \mu \mathrm{g} / \mathrm{ml}$ and $250 \mu \mathrm{g} / \mathrm{ml}$. Analysis was performed in triplicate.

\subsubsection{Statistical Studies}

Statistical analysis was conducted using Minitab $^{\circledR} 16$ software. A two-sample t-test was carried out comparing the particle size parameters for SD formulations and cryomilled HME formulations. A one-way analysis of variance (ANOVA) was carried out on the SD-F1, SDF2 and SD-F3 formulations comparing particle size d (0.5). A one-way ANOVA was also carried out on the HME-F1, HME-F2 and HME-F3 formulations comparing particle size following cryomilling. The drug release profiles of manufactured formulations were compared using a one-way ANOVA at each individual time point with a two-sample t-test being used to compare the release rates of both active ingredients from the slope of the line 
for the first 30 minutes of each formulation. In all statistical analyses, $p<0.05$ denoted significance. 


\section{Results and Discussion}

\subsection{Physiochemical characterization}

Both Kollidon $^{\circledR}$ VA 64 and Soluplus ${ }^{\circledast}$ were evaluated in this investigation as carriers for oral immediate release formulations. When incorporated into other formulations, these polymers have been shown to significantly increase the drug dissolution rate (Fule et al., 2016; Shamma and Basha, 2013; Song et al., 2013). Table 2 shows the composition of each formulation in the current study processed by SD and HME, with Table 3 showing the conditions used in the hot melt extruder at the various zones. The lowest possible extrusion temperature was used to produce an extrudate of the formulations outlined. PEG 3350 was included as a plasticiser for HME experiments (and the same formulation was then also processed by $\mathrm{SD}$ for comparison purposes). Low molecular weight PEGs have been reportedly used to improve handling and processing (Repka et al., 1999; Schilling et al., 2010, 2007; Wu and McGinity, 2001). The inclusion of PEG 3350 decreased the Tg of the system, and therefore allowed Kollidon ${ }^{\circledR}$ VA 64 to be processed at a lower temperature, below the thermal degradation of RAM. Thermal analysis (DSC and TGA) provides information about glass transition, melting and degradation temperatures (Mahmah et al., 2014). TGA was used to analyse the thermal degradation temperature of both polymers and APIs. HCTZ, was previously reported to be thermally stable over a wide range of temperatures (Valladao et al., 1996) (stable up to at least $301{ }^{\circ} \mathrm{C}$ ). This was verified in our studies, while RAM was shown to thermally degrade just above its melting point (at $123{ }^{\circ} \mathrm{C}$ ) (Supplemental Figure S 1).

As shown in Figure 1, both HCTZ and RAM displayed sharp melting endotherms at $272{ }^{\circ} \mathrm{C}$ and $117^{\circ} \mathrm{C}$, respectively, while Kollidon ${ }^{\circledR}$ VA 64 exhibited a glass transition temperature (Tg) at $108{ }^{\circ} \mathrm{C}$ and Soluplus ${ }^{\circledR}$ had a Tg at $77{ }^{\circ} \mathrm{C}$ (Supplemental Figure S 2). PEG 3350 is a semi-crystalline plasticizer that exhibits a melting endotherm at $60{ }^{\circ} \mathrm{C}$ (Supplemental Figure 
S 2). Polymers used in the study are thermally stable under the process conditions used in this study - PEG 3350 exhibits less than $1 \%$ weight loss up to $300{ }^{\circ} \mathrm{C}$, while Soluplus ${ }^{\circledR}$ and Kollidon ${ }^{\circledR}$ VA 64 start to degrade just over $280{ }^{\circ} \mathrm{C}$ (Supplemental Figure S 3). A maximum processing temperature of $140{ }^{\circ} \mathrm{C}$ was used to produce HME-F1 (i.e. formulation 1 processed by HME) and HME-F3. The extrusion temperature required is usually set to $15-60{ }^{\circ} \mathrm{C}$ above the glass transition of the system (Crowley, Michael M., 2007). The Tgs of HCTZ and RAM were determined for melt quenched materials and were found to be $112{ }^{\circ} \mathrm{C}$ and $2{ }^{\circ} \mathrm{C}$ respectively (Supplemental Figure S 4 and Supplemental Figure S 5).

PXRD diffractograms for all raw materials are shown in Figure 2. Both Kollidon ${ }^{\circledR}$ VA 64 and Soluplus $^{\circledast}$ are amorphous polymers, and lack crystalline peaks, instead showing a smooth halo. As it is crystalline in nature, HCTZ shows characteristic diffraction peaks at $16.65^{\circ}(2)$, $18.75^{\circ}(2), 21.40^{\circ}(2)$ and $24.65^{\circ}(2)$, which is consistent with the published literature (De Jaeghere et al., 2015; Panneerselvam et al., 2010). RAM also shows characteristic diffraction peaks at $7.60^{\circ}(2), 8.05^{\circ}(2), 19.30^{\circ}(2)$ and $21.25^{\circ}(2)$, consistent with the published literature (Jagdale et al., 2013; Madhavi et al., 2016). Unique characteristic peaks for HCTZ, RAM and PEG 3350 (semi-crystalline) can be seen in the PXRDs of physical mixtures of each of the formulations (Figure 3). For HCTZ, unique characteristic peaks are seen at $16.65^{\circ}(2), 20.9^{\circ}(2)$ and $24.65^{\circ}(2)$ in $\mathrm{F} 1, \mathrm{~F} 2$ and $\mathrm{F} 3$. For RAM, unique characteristic peaks are seen at $7.60^{\circ}(2)$ in F1, F2 and F3. For PEG 3350 a unique characteristic peak can be seen at $23.35^{\circ}(2)$ in $\mathrm{F} 2$ (which is the only formulation that contains the plasticiser). Formulations processed by SD show no characteristic peaks in the diffractograms (Figure 3), indicating that these formulations are completely PXRD amorphous. Formulations processed by HME on the other hand show characteristic peaks for HCTZ, and thus are partially crystalline. 
Modulated DSC (mDSC), which is known to be a more sensitive technique than standard DSC for measuring glass transition temperature (Tg) (Craig, 1995), was performed on all formulated products (Figure 4 and Figure 5). Figure 4 shows the reverse heat flow recorded for SD-F1 (i.e. formulation 1 processed by SD), SD-F2 and SD-F3. SD-F1 (Figure 4 (a)) has a clear single glass transition at $114{ }^{\circ} \mathrm{C}$, which indicates a homogenous molecular mix of all the formulation components in the amorphous system. SD-F2 and SD-F3 (Figure 4 (b) and (c)), which are also shown to be PXRD amorphous, show two clear glass transition temperatures in the reverse heat flow. This suggests a phase separation of the formulation components. Similarly, to the SD formulations, HME-F1 (Figure 5 (a)) shows one clear Tg at $104{ }^{\circ} \mathrm{C}$, with HME-F2 and HME-F3 (Figure 5 (b) and (c)) showing two separate glass transition events, which again suggests a phase separation. Formulations which undergo phase separation, show more than one Tg (Lin and Huang, 2010), in our case the two distinguishable $\operatorname{Tgs}$ are presumed to be due to a RAM/polymer rich zone and a HCTZ/polymer rich zone. The higher Tg is related to $\operatorname{HCTZ~}\left(\sim 112{ }^{\circ} \mathrm{C}\right)$ as it has a higher $\mathrm{Tg}$ than RAM $\left(\sim 2{ }^{\circ} \mathrm{C}\right)$. It was not possible to detect any endothermic peak for HCTZ at $272{ }^{\circ} \mathrm{C}$ as the formulations started to thermally degrade before this temperature and, as a result, distorted the heat flow signal. As can be seen in Figure 5, the Tgs determined for all three formulations produced by HME are lower than those observed for identical formulations produced by SD (shown in Figure 4). This is due to the increased crystalline HCTZ content in the HME formulations when compared to the fully PXRD amorphous systems produced by SD. According to the Gordon-Taylor equation (Gordon and Taylor, 1952), the weight fraction and density of individual amorphous components plays a critical role in the overall Tg of compatible amorphous blends. As HCTZ remains partially crystalline in the HME formulations, the weight fraction of RAM (which has a Tg of $2^{\circ} \mathrm{C}$ ) and the polymer carriers (both of which have lower Tg values than HCTZ) in the amorphous complex increase and 
have a greater influence over the overall $\mathrm{Tg} / \mathrm{Tgs}$, thus causing a $\mathrm{Tg}$ reduction relative to equivalent SD systems which have fully amorphous components.

With respect to the production of amorphous solid dispersions (ASD) through the different manufacturing processes, the most important factors are the solid state of the drug and its miscibility in the carrier system (Singh and Van den Mooter, 2016). All three spray dried formulations were amorphous, indicating sufficient component miscibility and intermolecular interactions to ensure molecular level mixing and ASD production. However, since all HME formulations were processed below the melting point of $\mathrm{HCTZ}\left(272^{\circ} \mathrm{C}\right)$, the formation of ASDs relies on the solubilization of the API components in the other formulation excipients (DiNunzio et al., 2010). As we are limited in our HME manufacturing process temperature due to the degradation of RAM above its melting point, the incomplete solubilization of HCTZ results in partially crystalline products.

When comparing the SD formulations to the HME formulations (post milling), there were significantly smaller particles for each spray dried formulation. As is to be expected with SD, the particles were in the micrometre size range. Once the extrudates for HME were pulverised into a powder, the milling process was stopped to minimise the impact it would have on the solid-state properties of the formulation. Particle size can decrease exponentially with time when milled (Suryanarayana, 2001) but this also increases the chances of milling changing the physical and solid state characteristics such as amorphous content of the HME formulation. While milling was undertaken at cryogenic temperatures to maintain amorphous content, local "hot spots" can develop due to the violent impact of balls during the milling process (Casale and Porter, 1979) which can promote crystallisation. For this reason, the milling process was conducted using the shortest timeframe possible. 
Fourier transform infrared spectroscopy (FT-IR) is one of the most widely used methods to detect the intermolecular interactions in ASDs, such as hydrogen bonds between API and polymer excipients (Van Eerdenbrugh and Taylor, 2011). For this reason, it was used to probe the presence of hydrogen bonding in the SD formulations.

In the HCTZ molecules, the $\mathrm{N}-\mathrm{H}$ and $\mathrm{N}-\mathrm{H}_{2}$ groups may act as hydrogen donors which can form hydrogen bonds with appropriate acceptor groups, such as a carbonyl $(C=O)$ groups. For the RAM molecule, the $\mathrm{N}-\mathrm{H}$ group and $\mathrm{O}-\mathrm{H}$ group are potential hydrogen donors. Kollidon $^{\circledR}$ VA 64 contains two hydrogen acceptors, which are derived from the $\mathrm{C}=\mathrm{O}$ groups of the pyrrolidone ring and the acetate structure. Hydrogen bonding of the API donor groups should preferentially involve the $\mathrm{C}=\mathrm{O}$ group of the pyrrolidone group, because this group is a stronger hydrogen bond acceptor than the acetate group (Kestur and Taylor, 2010; Taylor et al., 2001). For Soluplus ${ }^{\circledR}$, the $\mathrm{C}=\mathrm{O}$ groups of the caprolactam and acetate groups can act as hydrogen acceptors, with the $\mathrm{O}-\mathrm{H}$ groups acting as potential hydrogen donors.

The amorphous form of a given drug may give rise to a different IR spectrum than that obtained from the crystalline counterpart (Van Eerdenbrugh and Taylor, 2011). The crystalline form of HCTZ has clear peaks for its N-H group stretching at $3165 \mathrm{~cm}^{-1}, 3264 \mathrm{~cm}^{-}$ ${ }^{1}$ and $3360 \mathrm{~cm}^{-1}$ (Supplementary Figure S 6). In the amorphous form, we can see a downward shift in these bands with peak broadening. With crystalline RAM, O-H and N-H group stretching can be attributed to the peak seen at $3280 \mathrm{~cm}^{-1}$; however, this peak is shifted to $3027 \mathrm{~cm}^{-1}$ in the amorphous form. Similarly, the $\mathrm{C}=\mathrm{O}$ stretch peaks in the amorphous form of RAM shift downwards to $1643 \mathrm{~cm}^{-1}$ and $1734 \mathrm{~cm}^{-1}$ and broaden compared to the crystalline RAM peaks at $1651 \mathrm{~cm}^{-1}$ and $1742 \mathrm{~cm}^{-1}$. The reason for these differences between crystalline and amorphous API relate to both the wider range of conformations typically present in an amorphous solid and differences in intermolecular interactions (Van Eerdenbrugh and Taylor, 2011). Hence, when comparing physical mixtures to SD formulations, it is important that the 
physical mixtures contain amorphous excipients and amorphous APIs, rather than crystalline API raw materials. This has been shown previously by Taylor and Zografi (Taylor and Zografi, 1997) who demonstrated that for amorphous systems that contain more than one compound, the spectra of both the pure amorphous drugs and the amorphous excipients are needed in order to conclude the presence or absence of drug-polymer hydrogen bonds.

For F1 and F2, the N-H stretching of HCTZ at peaks $3165 \mathrm{~cm}^{-1}, 3264 \mathrm{~cm}^{-1}$ and $3360 \mathrm{~cm}^{-1}$, which are seen in the amorphous HCTZ, are not detected in the IR spectra for either the PM of amorphous components or the SD formulations (Supplementary Figure S 7). N-H stretching may downshift due to hydrogen bonding between drug and polymer components and be hidden by the C-H stretching peaks, which are seen between $2860 \mathrm{~cm}^{-1}$ and $2970 \mathrm{~cm}^{-1}$ for both the PM and SD systems. Another possible explanation for the absence of the peak attributable to N-H stretching of HCTZ in F1 and F2 PM and SD systems, may be that, due to the large polymer content, the signal is too weak to be detected. For the F1 and F2 formulations, peaks relating to the carbonyl groups of the pyrrolidone and acetate structures are at the same wavenumbers, i.e. $1662 \mathrm{~cm}^{-1}$ and $1732 \mathrm{~cm}^{-1}$ respectively, for both SD and PM systems. However, in the case of the SD formulation peaks are broader and of a higher intensity than their corresponding PM, which indicates the presence of hydrogen bonding with the API's hydrogen donors. Interestingly, for both SD-F1 and SD-F2 an additional peak is seen at $1599 \mathrm{~cm}^{-1}$, which is not present in the corresponding PM systems, and this is thought to correspond to an aromatic $\mathrm{C}=\mathrm{C}$ stretch or $\mathrm{N}-\mathrm{H}$ bending, which suggests a strong interaction taking place between the aromatic ring structures of both HCTZ and RAM. For F3, N-H stretching seen in the amorphous HCTZ can be detected in the PM but, like SD F1 and SD F2, this is not detectable in the SD F3 system. Again, as with SD F1 and SD F2, the C-H stretching peaks seen between $2860 \mathrm{~cm}^{-1}$ and $2925 \mathrm{~cm}^{-1}$ are broader and more intense 
than for the PM, which may be due to an overlap with N-H stretching which may downshift due to hydrogen bonding.

The carbonyl group $(\mathrm{C}=\mathrm{O})$ peaks seen at $1631 \mathrm{~cm}^{-1}$ and $1734 \mathrm{~cm}^{-1}$ in the SD F3 spectrum are broader than the corresponding peaks in the PM equivalent system. The broadened peak at $1631 \mathrm{~cm}^{-1}$ is also split, indicating hydrogen bonding interaction between the carbonyl groups and the hydrogen donor groups in the APIs. As Soluplus ${ }^{\circledR}$ also contains hydrogen donors in its structure we can clearly see evidence of an interaction between the sulfonyl groups $(\mathrm{O}=\mathrm{S}=\mathrm{O})$ in HCTZ and the alcohol donor groups in Soluplus ${ }^{\circledR}$, with a downshift peak movement in the SD formulation compared to the PM (Supplementary Figure S 7).

\subsection{Scanning Electron Microscopy}

The SEM images of HCTZ raw material exhibit particles with irregular shapes with clearly defined edges (Figure 6 (A)). The SEM images of RAM raw material display flat broken needles of varying sizes (Figure 6 (B)). SD-F1, SD-F2 and SD-F3 show partially spherical particles where the sphere surface was smooth with concave depressions (Figure 7 (A)-(C)) of the type previously seen when PVP (Paradkar et al., 2004) and Soluplus ${ }^{\circledR}$ (Homayouni et al., 2015) were spray dried. Once compressed into a disc for intrinsic dissolution studies, SDF1 and SD-F2 (Figure 7 (D) \& (E)) display a surface with more crevices/voids than SD-F3 (Figure $7(\mathrm{~F})$ ), most probably due to the different polymer viscoelastic properties. Polymers, in general, are viscoelastic materials and usually deform once sufficient pressure is applied. Kollidon $^{\circledR}$ VA 64 (Dashevsky et al., 2004; Kolter and Flick, 2000) and Soluplus ${ }^{\circledR}$ (Hughey et al., 2013; Zhong et al., 2016) polymers have been shown to be compressible into tablet formulations, which in turn enables discs to be successfully prepared in the Wood's apparatus for intrinsic dissolution studies. Kollidon ${ }^{\circledR}$ VA 64 displays very good plastic properties and for this reason it is often used as a binder in direct compression. Soluplus ${ }^{\circledR}$ on the other hand, has more elastic behaviour (Gupta et al., 2015) due to the storage modulus being greater than 
the loss modulus at temperatures below and close to its Tg (Gupta et al., 2016). The plastic properties of the Kollidon ${ }^{\circledR}$ VA 64 account for the cracks/voids forming, as the material will remain deformed, differing from its original configuration after compression force is applied. However, the elastic properties of the Soluplus ${ }^{\circledR}$ (Hughey et al., 2013; Zhong et al., 2016) account for fewer cracks/voids as the material tries to revert to its original configuration. HME-F1, HME-F2 and HME-F3 post milling show particles with asymmetrical shapes (Figure $8(\mathrm{~A})-(\mathrm{C})$ ). As one of our objectives was a direct comparison between products, it was decided that the extrudates would be cryomilled for the shortest amount of time that completely pulverised the extrudates to a powder using the cryomill. PXRD and mDSC analysis was conducted on HME formulation material to test for any potential physiochemical changes that may occur during the milling process. Cryomilling was chosen as previous studies have shown that, by milling at temperatures below the $\mathrm{Tg}$, amorphous components of formulations retain their amorphous content (Descamps et al., 2007). Post milling, PXRD and mDSC showed no statistical difference in peak intensity of crystalline components or change in Tgs present (data not shown). Once compressed into a disc for intrinsic dissolution studies, HME-F1 and HME-F2 (Figure 8 (D) and (E)) exhibit a surface with more crevices/voids than HME-F3 (Figure $8(\mathrm{~F})$ ) on the scale displayed. As with the SD formulations, the visual differences can most probably be attributed to the different viscoelastic properties of the polymers used in the formulations.

\subsection{Particle Size Analysis}

Particle size analysis (PSA) results for SD-F1, SD-F2 and SD-F3 were compared to the results of PSA for HME-F1, HME-F2 and HME-F3 systems post cryo-milling (Table 4). The SD-F1, SD-F2 and SD-F3 particle size are statistically different from one another (95\%CI, $\mathrm{P}<0.05$, F-value 181.37), which may be attributed to the different polymers and polymer compositions used. While SD parameters and solution concentrations remained constant, the 
only variable for SD formulations was the composition. It has been previously shown that formulation composition can result in varying particle size distribution when other conditions remain constant (Costantino et al., 2002; Oneda and Ré, 2003). The molecular weight of Kollidon $^{\circledR}$ VA 64 is between 45,000 - 70,000 g/mol (BASF, 2008) on average whereas the average molecular weight for Soluplus ${ }^{\circledR}$ is between 90,000 - 140,000 g/mol (BASF, 2010). PEG 3350 has an average molecular weight of $3350 \mathrm{~g} / \mathrm{mol}$. The greater the molecular weight, the longer the chain length resulting in more stiffness in the polymer structure, leading to larger particle size post SD processing (Gupta et al., 2016). The results in table 4, show the formulation with the largest molecular weight polymer (SD-F3) produced the largest particle size.

HME-F1 and HME-F2 were not statistically different from one another post-milling. However, HME-F3 was statistically different from HME-F1 and HME-F2 (95\%CI, P<0.05, F-value 25.05). It is thought that the reason HME-F1 and HME-F2 are different to HME-F3 is due to the formulation composition, as described above for SD formulations. HME-F1 and HME-F2 contain Kollidon ${ }^{\circledR}$ VA64 in both formulations with the addition of PEG 3350 in F2 not affecting the overall particle size post milling at its formulation concentration of $8.25 \%$. As HME-F3 contains a different polymer, namely Soluplus ${ }^{\circledR}$, it is thought that it behaves differently (due to its more elastic properties when compared to Kollidon ${ }^{\circledR}$ VA 64) in the cryo-mill, resulting in a different particle size distribution.

\subsection{Drug Assay}

Drug assays of pharmaceutical formulations are of great importance, as actual drug content must fall within specific limits of the manufacturer's label claims. Specific individual monographs exist in the British Pharmacopeia (BP) for both HCTZ and RAM in relation to acceptable limits for tablet drug content, although a monograph for a combination of the two 
APIs in a single oral tablet does not exist in the BP. HCTZ content is considered acceptable if the drug content is found to be between 92.5 to $107.5 \%$ of the stated amount (British Pharmacopoeia, 2018c). RAM content is considered acceptable if the drug content is found to be between 90.0 to $105.0 \%$ of the stated amount (British Pharmacopoeia, 2018d). It was decided that these drug content ranges would be acceptable for our formulations as ultimately, our final dosage form will be an oral tablet. It can be seen from the assay (table 5) that both HCTZ and RAM content fall within the desired ranges for each of the SD formulations. HCTZ content also falls within the desired range for each of the HME formulations, however RAM content does not. Due to the processing temperatures required for HME-F1 and HME-F3, RAM starts to degrade during the manufacturing process. There is a significant reduction in the RAM content for both HME-F1 and HME-F3. To overcome this problem, PEG 3350 was added to act as a plasticizer and allow us to process at a lower temperature for HME-F2. The reduction in the processing temperature resulted in the preservation of RAM content and brings the final drug content to acceptable levels.

\subsection{Dissolution Testing}

Intrinsic dissolution is described as particle size independent (Hendriksen, 1991; Wood et al., 1965) and is based on measurements taken from compacted powder discs of known surface area under controlled hydrodynamic conditions (Healy et al., 2002). The area exposed to the dissolution media remains constant over time. Therefore, the intrinsic dissolution rate depends on the solubility of the powder compact, the hydrodynamics of the system and the diffusion coefficient of the dissolving substance in the dissolution medium (Hendriksen, 1991; Wood et al., 1965).

The intrinsic dissolution studies for the SD and HME formulations were carried out over a 120-minute period. The intrinsic dissolution rate was calculated from the slope of the line for the first 30 minutes of the study as this is where a linear response was observed. After 30 
minutes, a non-linear response was observed for the release of HCTZ from SD-F1, SD-F2, HME-F1 and HME-F2, possibly due to the recrystallization of HCTZ in-situ. RAM continued to display linear release profiles up to 120 minutes (data not shown). The Wood's apparatus experiments were repeated for the SD particles and surface scrapings of the pellets were taken at 10 minute time point intervals up to 30 minutes to test for any recrystallisation at the pellet surface which may influence the rate of release. All SD pellets surfaces remained fully XRD amorphous up to the 30 minute time point (Supplemental Figure S 8).

It can be seen from the intrinsic dissolution results (Figure 9 and Figure 10, Table 5) that hot melt extrusion formulations showed a statistically significantly greater dissolution release rate for F1 and F2 for both $\mathrm{HCTZ}$ and RAM from the compressed discs. We were unable to establish any release profiles for F3 from either SD or HME products. The lack of drug release from SD-F3 and HME-F3 can be attributed to Soluplus ${ }^{\circledR}$. Soluplus ${ }^{\circledR}$, which was used in the manufacture of $\mathrm{F} 3$, is comprised of three different monomer components, namely, polyvinyl caprolactam, polyvinyl acetate and polyethylene glycol (Kolter et al., 2012). It should be noted that Soluplus ${ }^{\circledR}$ has been previously shown to be soluble at pH 1.2 (Sun and Lee, 2015), however, one component monomer, polyvinyl caprolactam, which is soluble in cold water, is no longer water soluble above $35^{\circ} \mathrm{C}$ (Kroker et al., 1995) which may result in reduced solubility of the polymer at the experimental temperature $\left(37^{\circ} \mathrm{C}\right)$. Soluplus ${ }^{\circledR}$ has also displayed properties of extensive swelling in dissolution media (Taupitz et al., 2013) resulting in a very slow dissolution rate of test material and, in our studies, polymer swelling was evident when discs were removed post dissolution. On contact with aqueous dissolution medium, Soluplus $^{\circledR}$ is known to enter the solution as single polymer chains which then organise into uni-chain polymer micelles (BASF, 2010). As the concentration of Soluplus ${ }^{\circledR}$ increases, the uni-chain micelles join together to form multi-chain ones. The lower critical solution temperature has been reported to be between $37^{\circ} \mathrm{C}$ (Ali et al., 2009) and $40{ }^{\circ} \mathrm{C}$ (Cavallari et al., 2016) for Soluplus ${ }^{\circledR}$ and at these temperatures the aspect of multi-chain 
polymer micelles forming is more relevant as the chains lose the hydration crown and progressively associate, decreasing their solubility and forming a cloudy suspension that can precipitate. This behaviour is responsible for the gel forming property of Soluplus ${ }^{\circledR}$ (Cavallari et al., 2016). Due to the polymer gelling and swelling it is possible that the intrinsic dissolution/constant surface area model is not suitable for dissolution testing with Soluplus ${ }^{\circledR}$ polymer even though it has been reported in the literature that Soluplus ${ }^{\circledR}$ has been shown to increase the solubility and dissolution rate of some APIs (Djuris et al., 2013; Homayouni et al., 2015; Linn et al., 2012; Shamma and Basha, 2013; Zhang et al., 2014).

\subsection{Surface topography}

As previously stated, all formulations produced by SD were amorphous in nature while formulations produced by HME remained partially crystalline. It is generally accepted that amorphous material has a higher solubility and dissolution rate than equivalent crystalline material, and thus the higher dissolution rates observed for HME systems was surprising.

From SEM images of the discs, the surface of HME discs appeared rougher than SD discs. It was hypothesised that this could lead to an increased turbulence in the hydrodynamic boundary layer for the HME compressed discs, resulting in a higher dissolution rate than for smoother SD compressed discs (Healy, Anne Marie et al., 1995; Healy and Corrigan, 1996). Surface topography analysis was conducted to study the surface roughness of the compressed discs. Surface roughness, which may be quantified by several parameters including Ra, the surface roughness average, is a measurement of surface finish - it is topography at a scale that might be considered "texture" on the surface. The roughness average is a quantitative calculation of the relative roughness of a linear profile or area, expressed as a single numeric parameter. Table 6 outlines the surface roughness average ( $\mathrm{Ra}$ ) for each of the compressed discs. The Ra values for SD formulations were compared to the Ra values for equivalent 
HME formulations. There is a statistically significant difference in Ra between SD-F1 and HME-F1 $($ T-value $=-11.85, \mathrm{p}<0.05)$ and SD-F2 and HME-F2 $($ T-value $=-8.38, \mathrm{p}<0.05)$. There is no statistically significant difference between the Ra of SD-F3 and HME-F3 (Tvalue $=-1.78, \mathrm{p}>0.05)$

While the Wood's apparatus is designed to minimise the effects particle size can have on the dissolution rate, it can be clearly shown from the results in table 6 and graphs in Figure 11, that the surface texture differs after compression between the SD and HME formulations. The differences in surface texture gives rise to varying turbulence levels at the hydrodynamic boundary layer and as a result the dissolution rates differ. Figure 11 provides a visual representation of the surfaces of the compacted discs and shows how the difference in manufacturing techniques and particle size leads to differences in the Ra of compacted discs.

\subsection{Stability Studies}

As molecular mobility allows for physical aging and recrystallization (Yoshioka et al., 1994) of glasses below their $\mathrm{Tg}$, the $\mathrm{Tg}$ is unsatisfactory as an indicator for the temperature below which mobility stops (Noyes and Whitney, 1897). As a general guide, it is accepted that the Tg-50 Kelvin rule should apply to allow for physical stability on long term storage (Hancock et al., 1995). Practically, the higher the Tg of an amorphous system, the longer it would be expected to remain stable in an amorphous state at relevant pharmaceutical temperatures (Hancock et al., 1995). As well as temperature, moisture also can induce recrystallization of amorphous formulations (Konno and Taylor, 2008; Makower and Dye, 1956). Water is able

to absorb and adsorb onto polar functional groups of hydrophilic polymers (Thibert and Hancock, 1996). The interaction of the water with the amorphous material lowers the $\mathrm{Tg}$ of the formulation due to its universal activity as a plasticiser (Szakonyi and Zelkó, 2012) water molecules may be able to penetrate into the hydrophilic polymer matrix, increasing the distance between polymer chains and thus resulting in greater free volume for molecular 
movement to occur (Abiad et al., 2009). SD and HME products were tested for stability at two different relative humidities, $\mathrm{RH}=75 \%$ and $\mathrm{RH}<10 \%$. Both conditions were maintained at $25{ }^{\circ} \mathrm{C}$.

All SD formulations remained completely PXRD amorphous at stability conditions $<10 \% \mathrm{RH} / 25^{\circ} \mathrm{C}$ throughout the entire stability study (60 days) (Supplemental Figure S 9 (a)(c)). mDSC studies showed similar results as for the initial products tested (at $\mathrm{t}=0$ ), with SDF1 displaying one clear $\mathrm{Tg}$ at $113{ }^{\circ} \mathrm{C}, \mathrm{SD}-\mathrm{F} 2$ displaying two clear $\mathrm{Tgs}$ at $52^{\circ} \mathrm{C}$ and $94{ }^{\circ} \mathrm{C}$ and SD-F3 displaying two Tgs at $59^{\circ} \mathrm{C}$ and $89^{\circ} \mathrm{C}$, respectively (Supplemental Figure $\mathrm{S} 10$ ) after 60 days on stability. For SD-F2 and SD-F3, phase separation was evident at the initial analysis time point and this remains the case at time point $t=60$ days, however, the formulations remain in an amorphous state. As previously stated, a homogenous molecularly dispersed system may be seen as favourable for long term stability of amorphous products due to the higher $\mathrm{Tg}$ value obtained but, below the $\mathrm{Tg}$ should phase separation be thermodynamically favoured, the characteristics of the system may offer significant barriers to recrystallization resulting in a stable system over pharmaceutical relevant time frames (Tian et al., 2013). HPLC analysis revealed both drugs remained within $100 \pm 5 \%$ of the stated drug content in each of the SD formulations over the 60 day stability study, with no degradation products present (data not shown).

SD-F1 and SD-F3 remained completely PXRD amorphous at stability conditions 75\%RH/25 ${ }^{\circ} \mathrm{C}$ throughout the entire stability study (Supplemental Figure S 11 (a) and (c)). SD-F2 remained PXRD amorphous up to $t=30$ days (data not shown), however by the final time point ( $\mathrm{t}=60$ days), the PEG 3350 in the formulation had partially recrystallized, which is evident by a unique PEG 3350 peak at $23.35^{\circ}(2$ ) (Supplemental Figure S 11 (b)) in the diffractogram. $\mathrm{mDSC}$ at time point $\mathrm{t}=60$ days for $\mathrm{SD}-\mathrm{F} 2$ also revealed an endothermic peak 
at $55{ }^{\circ} \mathrm{C}$ (Supplemental Figure S 12 (b)) in the reverse heat flow corresponding to PEG 3350 melting, which confirms partial crystallinity. mDSC showed similar results to the initial products tested (at $\mathrm{t}=0$ ) with $\mathrm{SD}-\mathrm{F} 1$ displaying one clear $\mathrm{Tg}$ at $114{ }^{\circ} \mathrm{C}$ and SD-F3 displaying two Tgs at $58{ }^{\circ} \mathrm{C}$ and $89{ }^{\circ} \mathrm{C}$, respectively. HPLC analysis revealed both APIs remained within $100 \pm 5 \%$ of the stated drug content in each of the SD formulations over the 60 day study (data not shown).

All HME formulations showed partial PXRD crystallinity for both stability conditions (25 ${ }^{\circ} \mathrm{C} /<10 \% \mathrm{RH}$, and $\left.25^{\circ} \mathrm{C} / 75 \% \mathrm{RH}\right)$ (Supplemental Figure S 9 (d)-(f), Supplemental Figure S 10 (d)-(f)) at time point $\mathrm{t}=60$ days when compared to the initial analysis. Peaks are evident at $16.6^{\circ}(2)$ in formulations HME-F1, HME-F2 and HME-F3, indicating partial recrystallization of $\mathrm{HCTZ}$, and $23.35^{\circ}(2)$ in HME-F2 (the only formulation containing PEG 3350), indicating recrystallization of PEG 3350. Partial PEG 3350 recrystallizations for HME-F2 at both stability conditions is confirmed with the presence of endothermic peaks in the mDSC at $51{ }^{\circ} \mathrm{C}$ (Supplemental Figure S 10 (e)) and $51{ }^{\circ} \mathrm{C}$ (Supplemental Figure S 12 (e)). HPLC analysis revealed both APIs remained at the initial drug content in each of the HME formulations with no degradation products present (data not shown).

From the PXRD and mDSC data we can see that the SD formulations offer greater long term amorphous stability than the HME formulations under the particular stability test conditions chosen. As the initial PXRD analysis demonstrated SD products to be completely PXRD amorphous and the HME products to be partially crystalline, the crystal components may encourage further crystal growth to occur throughout the product as time progresses, leading to decreased amorphous stability in the HME products when compared to SD products. Initial Tgs were also relatively lower for HME products when compared to SD products, which can 
result in decreased amorphous stability. Generally, a system with a higher $\mathrm{Tg}$ results in longer-term amorphous stability when compared to a system with a lower $\mathrm{Tg}$. 


\section{Conclusion}

The pharmaceutical industry is moving towards continuous manufacturing to produce pharmaceutical products rather than the traditional batch-based processes, and two continuous manufacturing techniques - hot melt extrusion and spray drying - were employed in this study to produce fixed dose combinations products. Depending on the desired characteristics of the final formulation, the method of manufacture has a critical impact upon the outcome. Both spray drying, and hot melt extrusion may be used to produce monolithic fixed dose combination products with an immediate release dissolution profile. However, spray drying may be a more suitable option if a thermolabile API is being processed due to the vast array of volatile solvents available, allowing processing to be conducted at a lower temperature than may be required in hot melt extrusion with the same formulation. On the other hand, required processing temperatures can be reduced if the addition of a plasticiser is feasible and appropriate for hot melt extrusion, potentially avoiding the degradation of the thermolabile API.

While the Wood's apparatus allows for comparison of release rates from a constant surface area, the surface roughness of the compacted disc may have a significant effect on the release rate. Also, formulations that contain polymers prone to swelling under the test conditions used may not be suited to a Wood's apparatus dissolution test.

Finally, as HCTZ is indicated with several ACE inhibitors, which have similar chemical structures to RAM, for the treatment of HPT, the spray drying and hot melt extrusion processes may be applicable to the manufacture of other FDCs containing HCTZ and another ACE inhibitor.

Thus, the present study demonstrates the importance of selecting the manufacturing method as well as polymer selection in the manufacture of stable monolithic fixed dose combination products. 


\section{Acknowledgements}

This investigation was conducted with the financial support of both the Department for the Economy of Northern Ireland and Science Foundation Ireland (SFI) under Grant Number 14/IA/2559.

The authors would like to thank Mr Colin Reid and Mrs. Leona O'Connor of the Irish Centre for Research in Applied Geosciences (iCRAG) for their assistance and guidance with the profilometry measurements.

\section{Appendix A. Supplementary material}

Supplementary data associated with this article can be found in the online version. 


\section{References}

Abiad, M.G., Carvajal, M.T., Campanella, O.H., 2009. A Review on Methods and Theories to Describe the Glass Transition Phenomenon: Applications in Food and Pharmaceutical Products. Food Eng. Rev. 1, 105-132. https://doi.org/10.1007/s12393-009-9009-1

Agrawal, A.M., Dudhedia, M.S., Zimny, E., 2016. Hot Melt Extrusion: Development of an Amorphous Solid Dispersion for an Insoluble Drug from Mini-scale to Clinical Scale. AAPS PharmSciTech 17, 133-147. https://doi.org/10.1208/s12249-015-0425-7

Ali, S., Langley, N., Djuric, D., Kolter, K., 2009. Eye on Excipients [WWW Document]. Basf. URL https://industries.basf.com/bin/bws/documentDownload.en.8805804190165 Ambrosioni, E., Borghi, C., Costa, F., 1987. Captopril and hydrochlorothiazide: rationale for their combination. Br. J. Clin. Pharmacol. 23, 43S-50S. https://doi.org/10.1111/j.13652125.1987.tb03121.x

Aulton, M.E., Taylor, K., 2013. Aulton's Pharmaceutics: The Design and Manufacture of Medicines, Fourth edi. ed. Elsevier Health Sciences,.

Badens, E., Majerik, V., Horvth, G., Szokonya, L., Bosc, N., Teillaud, E., Charbit, G., 2009. Comparison of solid dispersions produced by supercritical antisolvent and sprayfreezing technologies. Int. J. Pharm. 377, 25-34. https://doi.org/10.1016/j.ijpharm.2009.04.047

BASF, 2010. Technical Information Soluplus [WWW Document]. BASF, Pharma Ingredients Serv. URL https://pharmaceutical.basf.com/en/DrugFormulation/Soluplus.html

BASF, 2008. Technical Information Kollidon®VA64 [WWW Document]. BASF SE Care Chem. Div. Pharma Ingredients Serv. URL https://industries.basf.com/bin/bws/documentDownload.en.8805243988437

Blatnik, S.U., Dreu, R., Sr i , S., 2015. Influence of $\mathrm{pH}$ modifiers on the dissolution and stability of hydrochlorothiazide in the bi- and three-layer tablets. Acta Pharm. 65, 383- 
397. https://doi.org/10.1515/acph-2015-0031

Brayfield, A. (Ed.), 2014. Martindale - The Complete Drug Reference, Thirty-eig. ed. Pharmaceutical Press.

British Pharmacopoeia, 2018a. Hydrochlorothiazide Monograph [WWW Document]. Br.

Pharmacopoeia. URL https://www.pharmacopoeia.com/bp-

2018/monographs/hydrochlorothiazide.html?date=2018-01-

01\&text=hydrochlorothiazide (accessed 2.19.18).

British Pharmacopoeia, 2018b. Ramipril Monograph [WWW Document]. Br.

Pharmacopoeia. URL https://www.pharmacopoeia.com/bp-

2018/monographs/ramipril.html?date=2018-01-01\&text=Ramipril (accessed 2.19.18).

British Pharmacopoeia, 2018c. Hydrochlorothiazide Tablets Monograph [WWW Document].

Br. Pharmacopoeia. URL https://www.pharmacopoeia.com/bp-2018/formulatedspecific/hydrochlorothiazide-tablets.html?date=2018-01-01\&text=hydrochlorothiazide

British Pharmacopoeia, 2018d. Ramipril Tablets Monograph [WWW Document]. Br.

Pharmacopoeia. URL https://www.pharmacopoeia.com/bp-2018/formulatedspecific/ramipril-tablets.html?date=2018-01-01\&text=ramipril (accessed 2.19.18).

Brown, C.L., Backhouse, C.I., Grippat, J.C., Santoni, J.P., 1990. The effect of perindopril and hydrochlorothiazide alone and in combination on blood pressure and on the reninangiotensin system in hypertensive subjects. Eur. J. Clin. Pharmacol. 39, 327-332.

Casale, A., Porter, R.S. (Roger S., 1979. Polymer stress reactions, Volume 2. Academic Press.

Cavallari, C., Ternullo, S., Tarterini, F., Fini, A., 2016. Release Problems for Nifedipine in the Presence of Soluplus 3, 1-13. https://doi.org/10.15436/2377-1313.16.020

Chrysant, S.G., 1994. Antihypertensive effectiveness of low-dose lisinoprilhydrochlorothiazide combination. A large multicenter study. LisinoprilHydrochlorothiazide Group. Arch. Intern. Med. 154, 737-743. 
Costantino, H.R., Firouzabadian, L., Wu, C., Carrasquillo, K.G., Griebenow, K., Zale, S.E., Tracy, M.A., 2002. Protein spray freeze drying. 2. Effect of formulation variables on particle size and stability. J. Pharm. Sci. 91, 388-395.

Craig, D.Q.M., 1995. A review of thermal methods used for the analysis of the crystal form, solution thermodynamics and glass transition behaviour of polyethylene glycols. Thermochim. Acta 248, 189-203. https://doi.org/10.1016/0040-6031(94)01886-L

Crowley, Michael M., Z.F., 2007. Pharmaceutical Applications of Hot-Melt Extrusion: Part I Review Article. Drug Dev. Ind. Pharm. 33, 909-926. https://doi.org/10.1080/03639040701498759

Dashevsky, A., Kolter, K., Bodmeier, R., 2004. Compression of pellets coated with various aqueous polymer dispersions. Int. J. Pharm. 279, 19-26.

https://doi.org/10.1016/j.ijpharm.2004.03.019

De Jaeghere, W., De Beer, T., Van Bocxlaer, J., Remon, J.P., Vervaet, C., 2015. Hot-melt extrusion of polyvinyl alcohol for oral immediate release applications. Int. J. Pharm. 492, 1-9. https://doi.org/10.1016/j.ijpharm.2015.07.009

Descamps, M., Willart, J.F., Dudognon, E., Caron, V., 2007. Transformation of pharmaceutical compounds upon milling and comilling: The role of Tg. J. Pharm. Sci. 96, 1398-1407. https://doi.org/10.1002/jps.20939

Dierickx, L., Saerens, L., Almeida, A., De Beer, T., Remon, J.P., Vervaet, C., 2012. Coextrusion as manufacturing technique for fixed-dose combination mini-matrices. Eur. J. Pharm. Biopharm. 81, 683-689. https://doi.org/10.1016/j.ejpb.2012.03.018

DiNunzio, J.C., Brough, C., Hughey, J.R., Miller, D.A., Williams, R.O., McGinity, J.W., 2010. Fusion production of solid dispersions containing a heat-sensitive active ingredient by hot melt extrusion and Kinetisol® dispersing. Eur. J. Pharm. Biopharm. 74, 340-351. https://doi.org/10.1016/J.EJPB.2009.09.007

Djuris, J., Nikolakakis, I., Ibric, S., Djuric, Z., Kachrimanis, K., 2013. Preparation of 
carbamazepine-Soluplus solid dispersions by hot-melt extrusion, and prediction of drugpolymer miscibility by thermodynamic model fitting. Eur. J. Pharm. Biopharm. 84, 228237. https://doi.org/10.1016/j.ejpb.2012.12.018

Dunn, P.J., Wells, A.S., Williams, M.T., 2010. Future Trends for Green Chemistry in the Pharmaceutical Industry, in: Green Chemistry in the Pharmaceutical Industry. WileyVCH Verlag GmbH \& Co. KGaA, Weinheim, Germany. https://doi.org/10.1002/9783527629688.ch16

Farrell, B., Shamji, S., Monahan, A., French Merkley, V., 2013. Reducing polypharmacy in the elderly: Cases to help you \&quot;rock the boat\&quot;. Can. Pharm. J. (Ott). 146, 243-4. https://doi.org/10.1177/1715163513499530

Fule, R., Paithankar, V., Amin, P., 2016. Hot melt extrusion based solid solution approach: Exploring polymer comparison, physicochemical characterization and in-vivo evaluation. Int. J. Pharm. 499, 280-294. https://doi.org/10.1016/j.ijpharm.2015.12.062

Gautam, C.S., Saha, L., 2008. Fixed dose drug combinations (FDCs): Rational or irrational: A view point. Br. J. Clin. Pharmacol. 65, 795-796. https://doi.org/10.1111/j.13652125.2007.03089.x

Ghadi, R., Dand, N., 2017. BCS class IV drugs: Highly notorious candidates for formulation development. J. Control. Release 248, 71-95. https://doi.org/10.1016/J.JCONREL.2017.01.014

Gordon, M., Taylor, J.S., 1952. Ideal copolymers and the second-order transitions of synthetic rubbers. i. non-crystalline copolymers. J. Appl. Chem. 2, 493-500. https://doi.org/10.1002/jctb.5010020901

Guns, S., Dereymaker, A., Kayaert, P., Mathot, V., Martens, J.A., Van Den Mooter, G., 2011. Comparison between hot-melt extrusion and spray-drying for manufacturing solid dispersions of the graft copolymer of ethylene glycol and vinylalcohol. Pharm. Res. 28, 673-682. https://doi.org/10.1007/s11095-010-0324-2 
Gupta, S.S., Parikh, T., Meena, A.K., Mahajan, N., Vitez, I., Serajuddin, A.T.M., 2015. Effect of carbamazepine on viscoelastic properties and hot melt extrudability of Soluplus (R). Int. J. Pharm. 478, 232-239. https://doi.org/10.1016/j.ijpharm.2014.11.025

Gupta, S.S., Solanki, N., Serajuddin, A.T.M., 2016. Investigation of Thermal and Viscoelastic Properties of Polymers Relevant to Hot Melt Extrusion, IV: Affinisol ${ }^{\mathrm{TM}}$ HPMC HME Polymers. AAPS PharmSciTech 17, 148-157. https://doi.org/10.1208/s12249-015-0426-6

Gursch, J., Hohl, R., Armenante, M.E., Dujmovic, D., Van Der Wel, P., Brozio, J., Krumme, M., Rasenack, N., Khinast, J., 2015. Continuous Drying of Small Particles for Pharmaceutical Applications - An Evaluation of Selected Lab-Scale Systems. Org. Process Res. Dev. 19, 2055-2066. https://doi.org/10.1021/acs.oprd.5b00309

Hancock, B.C., Shamblin, S.L., Zografi, G., 1995. Molecular Mobility of Amorphous Pharmaceutical Solids Below Their Glass Transition Temperatures. Pharm. Res. 12, 799-806. https://doi.org/10.1023/A:1016292416526

Hao, J., Rodriguez-Monguio, R., Seoane-Vazquez, E., 2015. Fixed-dose combination drug approvals, patents and market exclusivities compared to single active ingredient pharmaceuticals. PLoS One 10,1-13. https://doi.org/10.1371/journal.pone.0140708

Healy, Anne Marie, Corrigan, O., Allen, J.E.M., 1995. The effect of dissolution on the surface texture of model solid-dosage forms as assessed by non-contact laser profilometry. Pharm. Technol. Eur. 9, 14-22.

Healy, A.M., Corrigan, O.I., 1996. The influence of excipient particle size, solubility and acid strength on the dissolution of an acidic drug from two-component compacts. Int. J.

Pharm. 143, 211-221. https://doi.org/10.1016/S0378-5173(96)04705-9

Healy, A.M., McCarthy, L.G., Gallagher, K.M., Corrigan, O.I., 2002. Sensitivity of dissolution rate to location in the paddle dissolution apparatus. J. Pharm. Pharmacol. 54, 441-4. https://doi.org/10.1211/0022357021778529 
Hendriksen, B.A., 1991. Characterization of calcium fenoprofen: 3. Mechanism of dissolution from rotating discs. Int. J. Pharm. 75, 63-72. https://doi.org/http://dx.doi.org/10.1016/0378-5173(91)90251-I

Homayouni, A., Sadeghi, F., Nokhodchi, A., Varshosaz, J., Afrasiabi Garekani, H., 2015. Preparation and characterization of celecoxib dispersions in soluplus $((\mathrm{R}))$ : comparison of spray drying and conventional methods. Iran. J. Pharm. Res. IJPR 14, 35-50.

Huang, S., Donnell, K.P.O., Delpon, S.M., Vaux, D., Brien, J.O., Stutzman, J., Williams, R.O., 2017. European Journal of Pharmaceutics and Biopharmaceutics Processing thermally labile drugs by hot-melt extrusion॰: The lesson with. Eur. J. Pharm. Biopharm. 119, 56-67. https://doi.org/10.1016/j.ejpb.2017.05.014

Hughey, J.R., Keen, J.M., Miller, D.A., Kolter, K., Langley, N., McGinity, J.W., 2013. The use of inorganic salts to improve the dissolution characteristics of tablets containing Soluplus(R)-based solid dispersions. Eur. J. Pharm. Sci. 48, 758-766. https://doi.org/10.1016/j.ejps.2013.01.004

Jagdale, S.C., Dangat, Y.T., Kuchekar, B.S., 2013. Solubility enhancement and formulation of buccal patches of Ramipril cyclodextrin complex. Asian J. Pharm. Clin. Res. 6, 8390.

Kestur, U.S., Taylor, L.S., 2010. Role of polymer chemistry in influencing crystal growth rates from amorphous felodipine. CrystEngComm 12, 2390. https://doi.org/10.1039/c001905d

Klein, A., Shah, V.P., 2008. A standardized mini paddle apparatus as an alternative to the standard paddle. AAPS PharmSciTech 9, 1179-1184. https://doi.org/10.1208/s12249008-9161-6

Kolter, K., Flick, D., 2000. Structure and dry binding activity of different polymers, including Kollidon® VA 64. Drug Dev. Ind. Pharm. 26, 1159-1165. https://doi.org/10.1081/DDC100100987 
Kolter, K., Karl, M., Gryczke, A., 2012. Hot-Melt Extrusion with BASF Pharma Polymers, Hot-Melt Extrusion with BASF Pharma Polymers.

Konno, H., Taylor, L.S., 2008. Ability of Different Polymers to Inhibit the Crystallization of Amorphous Felodipine in the Presence of Moisture. Pharm. Res. 25, 969-978. https://doi.org/10.1007/s11095-007-9331-3

Kroker, J., Schneider, R., Schupp, E., Kerber, M., 1995. Process for preparing aqueous solutions of poly(N-vinyl- -caprolactam) and their use.

Lee, S.., 2015. Modernizing Pharmaceutical Manufacturing: from Batch to Continuous Production. J. Pharm. Innov. 10, 191-199.

Lin, D., Huang, Y., 2010. A thermal analysis method to predict the complete phase diagram of drug-polymer solid dispersions. Int. J. Pharm. 399, 109-115. https://doi.org/http://dx.doi.org/10.1016/j.ijpharm.2010.08.013

Lindenberg, M., Kopp, S., Dressman, J.B., 2004. Classification of orally administered drugs on the World Health Organization Model list of Essential Medicines according to the biopharmaceutics classification system. Eur. J. Pharm. Biopharm. 58, 265-278. https://doi.org/10.1016/J.EJPB.2004.03.001

Linn, M., Collnot, E.M., Djuric, D., Hempel, K., Fabian, E., Kolter, K., Lehr, C.M., 2012. Soluplus® as an effective absorption enhancer of poorly soluble drugs in vitro and in vivo. Eur. J. Pharm. Sci. 45, 336-343. https://doi.org/10.1016/j.ejps.2011.11.025

Löbenberg, R., Amidon, G.L., 2000. Modern bioavailability, bioequivalence and biopharmaceutics classification system. New scientific approaches to international regulatory standards. Eur. J. Pharm. Biopharm. 50, 3-12. https://doi.org/10.1016/S09396411(00)00091-6

Madhavi, K., Shikha, A., Suresh, B., 2016. Formulation and in vitro characterization solid self emulsifying drug delivery system of ramipril prepared by adsorption technique. Int. J. Curr. Pharm. Res. 8, 40-45. 
Mahmah, O., Tabbakh, R., Kelly, A., Paradkar, A., 2014. A comparative study of the effect of spray drying and hot-melt extrusion on the properties of amorphous solid dispersions containing felodipine. J. Pharm. Pharmacol. 66, 275-284.

https://doi.org/10.1111/jphp.12099

Makower, B., Dye, W.B., 1956. Equilibrium Moisture Content and Crystallization of Amorphous Sucrose and Glucose. J. Agric. Food Chem. 4, 72-77. https://doi.org/10.1021/jf60059a010

McKenzie, P., Kiang, S., Tom, J., Rubin, A.E., Futran, M., 2006. Can pharmaceutical process development become high tech? AIChE J. 52, 3990-3994. https://doi.org/10.1002/aic.11022

Noyes, A.A., Whitney, W.R., 1897. The rate of solution of solid substances in their own solutions. J. Am. Chem. Soc. 19, 930-934. https://doi.org/10.1021/ja02086a003

O’Neill, M.J. (Ed.), 2013. The Merck index•: an encyclopedia of chemicals, drugs, and biologicals, Fifteenth. ed. Royal Society of Chemistry.

Oneda, F., Ré, M.I., 2003. The effect of formulation variables on the dissolution and physical properties of spray-dried microspheres containing organic salts. Powder Technol. 130, 377-384. https://doi.org/https://doi.org/10.1016/S0032-5910(02)00239-5

Panneerselvam, M., Natrajan, R., Selvaraj, S., Rajendran, N.N., 2010. A novel drug-drug solid dispersion of hydrochlorothiazide - losartan potassium. Int. Jounal Pharma Biosci. $1,68-80$.

Paradkar, A., Ambike, A.A., Jadhav, B.K., Mahadik, K.R., 2004. Characterization of curcumin-PVP solid dispersion obtained by spray drying. Int. J. Pharm. 271, 281-286. https://doi.org/10.1016/j.ijpharm.2003.11.014

Patil, H., Tiwari, R. V., Repka, M.A., 2015. Hot-Melt Extrusion: from Theory to Application in Pharmaceutical Formulation. AAPS PharmSciTech 17, 20-42. https://doi.org/10.1208/s12249-015-0360-7 
Polli, J.E., Yu, L.X., Cook, J.A., Amidon, G.L., Borchardt, R.T., Burnside, B.A., Burton, P.S., Chen, M., Conner, D.P., Faustino, P.J., Hawi, A.A., Hussain, A.S., Joshi, H.N., Kwei, G., Lee, V.H.L., Lesko, L.J., Lipper, R.A., Loper, A.E., Nerurkar, S.G., Polli, J.W., Sanvordeker, D.R., Taneja, R., Uppoor, R.S., Vattikonda, C.S., Wilding, I., Zhang, G., 2004. Summary workshop report: Biopharmaceutics classification systemimplementation challenges and extension opportunities, Journal of Pharmaceutical Sciences. Elsevier. https://doi.org/10.1002/jps.20064

Ramirez, E., Laosa, O., Guerra, P., Duque, B., Mosquera, B., Borobia, A.M., Lei, S.H., Carcas, A.J., Frias, J., 2010. Acceptability and characteristics of 124 human bioequivalence studies with active substances classified according to the Biopharmaceutic Classification System. Br. J. Clin. Pharmacol. 70, 694-702. https://doi.org/10.1111/j.1365-2125.2010.03757.x

Repka, M. a, Gerding, T.G., Repka, S.L., McGinity, J.W., 1999. Influence of plasticizers and drugs on the physical-mechanical properties of hydroxypropylcellulose films prepared by hot melt extrusion. Drug Dev. Ind. Pharm. 25, 625-633. https://doi.org/10.1081/DDC-100102218

Riekes, M.K., Kuminek, G., Rauber, G.S., De Campos, C.E.M., Bortoluzzi, A.J., Stulzer, H.K., 2014. HPMC as a potential enhancer of nimodipine biopharmaceutical properties via ball-milled solid dispersions. Carbohydr. Polym. 99, 474-482. https://doi.org/10.1016/j.carbpol.2013.08.046

Sanphui, P., Kusum Devi, V., Clara, D., Malviya, N., Ganguly, S., Desiraju, G.R., 2015. Cocrystals of Hydrochlorothiazide: Solubility and Diffusion/ Permeability Enhancements through Drug-Coformer Interactions. Mol. Pharm. 12, 1615-1622. https://doi.org/10.1021/acs.molpharmaceut.5b00020

Schilling, S.U., Lirola, H.L., Shah, N.H., Malick, A.W., Mcginity, J.W., 2010. Influence of plasticizer type and level on the properties of Eudragit S100 matrix pellets prepared by 
hot-melt extrusion. J. Microencapsul. 27, 521-532.

https://doi.org/10.3109/02652048.2010.484105

Schilling, S.U., Shah, N.H., Malick, a W., Infeld, M.H., McGinity, J.W., 2007. Citric acid as a solid-state plasticizer for Eudragit RS PO. J. Pharm. Pharmacol. 59, 1493-1500. https://doi.org/10.1211/jpp.59.11.0005

Scholze, J., Breitstadt, A., Cairns, V., Bauer, B., Bender, N., Priestley, C., Moreadith, C., Phillips, J., Vander Elst, E., Koch, G., 1993. Short report: ramipril and hydrochlorothiazide combination therapy in hypertension: a clinical trial of factorial design. The East Germany Collaborative Trial Group. J. Hypertens. 11, 217-221.

Sethia, S., Squillante, E., 2004. Solid dispersion of carbamazepine in PVP K30 by conventional solvent evaporation and supercritical methods. Int. J. Pharm. 272, 1-10. https://doi.org/10.1016/j.ijpharm.2003.11.025

Shamma, R.N., Basha, M., 2013. Soluplus $\circledR_{\bullet}:$ A novel polymeric solubilizer for optimization of Carvedilol solid dispersions $\bullet$ : Formulation design and effect of method of preparation. Powder Technol. 237, 406-414. https://doi.org/10.1016/j.powtec.2012.12.038

Singh, A., Van den Mooter, G., 2016. Spray drying formulation of amorphous solid dispersions. Adv, Drug Deliv. Rev. 100, 27-50. https://doi.org/10.1016/J.ADDR.2015.12.010

Song, Y., Wang, L., Yang, P., Wenslow, R.M., Tan, B., Zhang, H., Deng, Z., 2013. Physicochemical characterization of felodipine-kollidon VA64 amorphous solid dispersions prepared by hot-melt extrusion. J. Pharm. Sci. 102, 1915-1923. https://doi.org/10.1002/jps.23538

Sun, D.D., Lee, P.I., 2015. Probing the mechanisms of drug release from amorphous solid dispersions in medium-soluble and medium-insoluble carriers. J. Control. Release 211, 85-93. https://doi.org/10.1016/j.jconrel.2015.06.004 
Suryanarayana, C., 2001. Mechanical alloying and milling. Prog. Mater. Sci. 46, 1-184. https://doi.org/http://dx.doi.org/10.1016/S0079-6425(99)00010-9

Szakonyi, G., Zelkó, R., 2012. The effect of water on the solid state characteristics of pharmaceutical excipients: Molecular mechanisms, measurement techniques, and quality aspects of final dosage form. Int. J. Pharm. Investig. 2, 18-25. https://doi.org/10.4103/2230-973X.96922

Tajber, L., Corrigan, O.I., Healy, A.M., 2005. Physicochemical evaluation of PVP-thiazide diuretic interactions in co-spray-dried composites - Analysis of glass transition composition relationships. Eur. J. Pharm. Sci. 24, 553-563. https://doi.org/10.1016/j.ejps.2005.01.007

Taupitz, T., Dressman, J.B., Buchanan, C.M., Klein, S., 2013. Cyclodextrin-water soluble polymer ternary complexes enhance the solubility and dissolution behaviour of poorly soluble drugs. Case example: Itraconazole. Eur. J. Pharm. Biopharm. 83, 378-387. https://doi.org/10.1016/j.ejpb.2012.11.003

Taylor, L.S., Langkilde, F.W., Zografi, G., 2001. Fourier transform Raman spectroscopic study of the interaction of water vapor with amorphous polymers. J. Pharm. Sci. 90, 888-901. https://doi.org/10.1002/jps.1041

Taylor, L.S., Zografi, G., 1997. Spectroscopic characterization of interactions between PVP and indomethacin in amorphous molecular dispersions. Pharm. Res. 14, 1691-8.

Thibert, R., Hancock, B.C., 1996. Direct visualization of Superdisintegrant Hydration Using Environmental Scanning Electron Microscopy. J. Pharm. Sci. 85, 1255-1258. https://doi.org/http://dx.doi.org/10.1021/js960188d

Tian, Y., Booth, J., Meehan, E., Jones, D.S., Li, S., Andrews, G.P., 2013. Construction of drug-polymer thermodynamic phase diagrams using flory-huggins interaction theory: Identifying the relevance of temperature and drug weight fraction to phase separation within solid dispersions. Mol. Pharm. 10, 236-248. https://doi.org/10.1021/mp300386v 
Valladao, D.M.S., De Oliveira, L.C.S., Netto, J.Z., Ionashiro, M., 1996. Thermal decomposition of some diuretic agents. J. Therm. Anal. 46, 1291-1299. https://doi.org/10.1007/BF01979243

Van Eerdenbrugh, B., Taylor, L.S., 2011. Application of mid-IR spectroscopy for the characterization of pharmaceutical systems. Int. J. Pharm. 417, 3-16. https://doi.org/10.1016/J.IJPHARM.2010.12.011

Vynckier, A.K., Dierickx, L., Saerens, L., Voorspoels, J., Gonnissen, Y., De Beer, T., Vervaet, C., Remon, J.P., 2014. Hot-melt co-extrusion for the production of fixed-dose combination products with a controlled release ethylcellulose matrix core. Int. J. Pharm. 464, 65-74. https://doi.org/10.1016/j.ijpharm.2014.01.028

Vynckier, A.K., Lin, H., Zeitler, J.A., Willart, J.F., Bongaers, E., Voorspoels, J., Remon, J.P., Vervaet, C., 2015. Calendering as a direct shaping tool for the continuous production of fixed-dose combination products via co-extrusion. Eur. J. Pharm. Biopharm. 96, 125131. https://doi.org/10.1016/j.ejpb.2015.07.023

Wood, J.H., Syarto, J.E., Letterman, H., 1965. Improved holder for intrinsic dissolution rate studies. J. Pharm. Sci. 54, 1068. https://doi.org/10.1002/jps.2600540730

World Health Organization, 2017. WHO Model List of Essential Medicines 20th edition [WWW Document]. Essent. Med. Heal. Prod. URL http://www.who.int/entity/medicines/publications/essentialmedicines/20th_EML2017_F INAL_amendedAug2017.pdf?ua=1 (accessed 2.1.18).

World Health Organization, 2016. Cardiovascular diseases (CVDs) [WWW Document]. URL http://www.who.int/cardiovascular_diseases/en/

Wu, C., McGinity, J.W., 2001. Influence of ibuprofen as a solid-state plasticizer in Eudragit RS 30 D on the physicochemical properties of coated beads. AAPS PharmSciTech 2, 19. https://doi.org/10.1007/BF02830564

Yoshioka, M., Hancock, B.C., Zografi, G., 1994. Crystallization of Indomethacin from the 
Amorphous State below and above Its Glass Transition Temperature. J. Pharm. Sci. 83, 1700-1705. https://doi.org/http://dx.doi.org/10.1002/jps.2600831211

Yu, L.X., Straughn, A.B., Faustino, P.J., Yang, Y., Parekh, A., Ciavarella, A.B., AsafuAdjaye, E., Mehta, M.U., Conner, D.P., Lesko, L.J., Hussain, A.S., 2004. The effect of food on the relative bioavailability of rapidly dissolving immediate-release solid oral products containing highly soluble drugs. Mol. Pharm. 1, 357-362.

Zaid, A.N., Ghanem, M., Maqboul, L., Zaid, H., Mahasne, A., 2016. Biowaiver Eligibility of a Lower Strength Ramipril/Hydrochlorothiazide Immediate Release Tablets Using a New Validated HPLC Analytical Method. Drug Res. (Stuttg). 66, 539-546. https://doi.org/10.1055/s-0042-111434

Zhang, Y., Liu, Y., Luo, Y., Yao, Q., Zhong, Y., Tian, B., Tang, X., 2014. Extruded Soluplus/SIM as an oral delivery system: characterization, interactions, in vitro and in vivo evaluations. Drug Deliv. 7544. https://doi.org/10.3109/10717544.2014.960982 Zhong, Y., Jing, G., Tian, B., Huang, H., Zhang, Y., Gou, J., Tang, X., He, H., Wang, Y., 2016. Supersaturation induced by Itraconazole/Soluplus ${ }^{\circledR}$ micelles provided high GI absorption in vivo. Asian J. Pharm. Sci. 11, 255-264.

https://doi.org/10.1016/j.ajps.2015.07.001 


\section{List of Figures:}

A Comparative Study between Hot-Melt Extrusion and Spray-Drying for the Manufacture of Anti-Hypertension Compatible Monolithic Fixed-Dose Combination Products

J. F. Kelleher ${ }^{1}$, G. C. Gilvary ${ }^{2}$, A. M. Madi ${ }^{1}$, D. S. Jones ${ }^{2}$, S. Li ${ }^{2}$, Y. Tian ${ }^{2}$, A. Almajaan ${ }^{2}$, Z. Senta-Loys ${ }^{2}$, G. P. Andrews ${ }^{2}$, A. M. Healy ${ }^{1}{ }^{*}$ Affiliation

${ }^{1}$ School of Pharmacy and Pharmaceutical Sciences, Trinity College Dublin, Dublin, Ireland

${ }^{2}$ School of Pharmacy, Queen's University of Belfast, Belfast, Northern Ireland

*To whom correspondence should be addressed to:

Anne Marie Healy

Tel: +35318961444

Email: healyam@tcd.ie

Figure 1. DSC thermogram of API raw materials, with a heating rate of $10{ }^{\circ} \mathrm{C} / \mathrm{min}$. RAM shows a melting endotherm at $\sim 116^{\circ} \mathrm{C}$ and $\mathrm{HCTZ}$ shows a melting endotherm at $\sim 272{ }^{\circ} \mathrm{C}$.

Figure 2. PXRD of raw materials over the range of 5 40 ${ }^{\circ} 2 \theta$ of (a) HCTZ, (b) RAM, (c) Kollidon ${ }^{\circledR}$ VA 64, (d) Soluplus ${ }^{\circledR}$, (e) PEG 3350

Figure 3. PXRD of Spray Dried (SD), Hot Melt Extruded (HME) and Physical Mixtures (PM) of formulations $(F 1, F 2, F 3)$ from table 1 over the range of $5 \sim 40^{\circ} 2 \theta(a) S D-F 1,(b)$ 
SD-F2, (c) SD-F3, (d) HME-F1, (e) HME-F2, (f) HME-F3, (g) PM-F1, (h) PM-F2, (i) PMF3

Figure 4. DSC thermograms showing the reverse heat flow (W/g) signal for (a) SD-F1 (b) $S D-F 2$ and (c) SD-F3

Figure 5. DSC thermograms showing the reverse heat flow (W/g) for (a) HME-F1(b) HMEF2 and (c) HME-F3

Figure 6. SEM micrographs of (A) HCTZ raw material, (B) RAM raw material

Figure 7. $S E M$ of (A) $S D-F 1,(B) S D-F 2$, (C) SD-F3, (D) compressed disc $S D-F 1$, (E) compressed disc SD-F2, (F) compressed disc SD-F3

Figure 8. SEM of (A)HME-F1, (B) HME-F2, (C) HME-F3, (D) compressed disc HME-F1, (E) compressed disc HME-F2, (F) compressed disc HME-F3

Figure 9. Intrinsic release rate of (a) HCTZ from $S D-F 1$ and $H M E-F 1$, (b) RAM from $S D-F 1$ and $H M E-F I$

Figure 10. Intrinsic dissolution rate of (a) HCTZ from SD-F2 and HME-F2, (b) RAM from SD-F2 and HME-F2

Figure 11. 3D graphs following surface topography measurements of (a) $S D-F 1$, (b) $S D-F 2$, (c) SD-F3, (d) HME-F1, (e) HME-F2 and (f) HME-F3 
Figure 1.
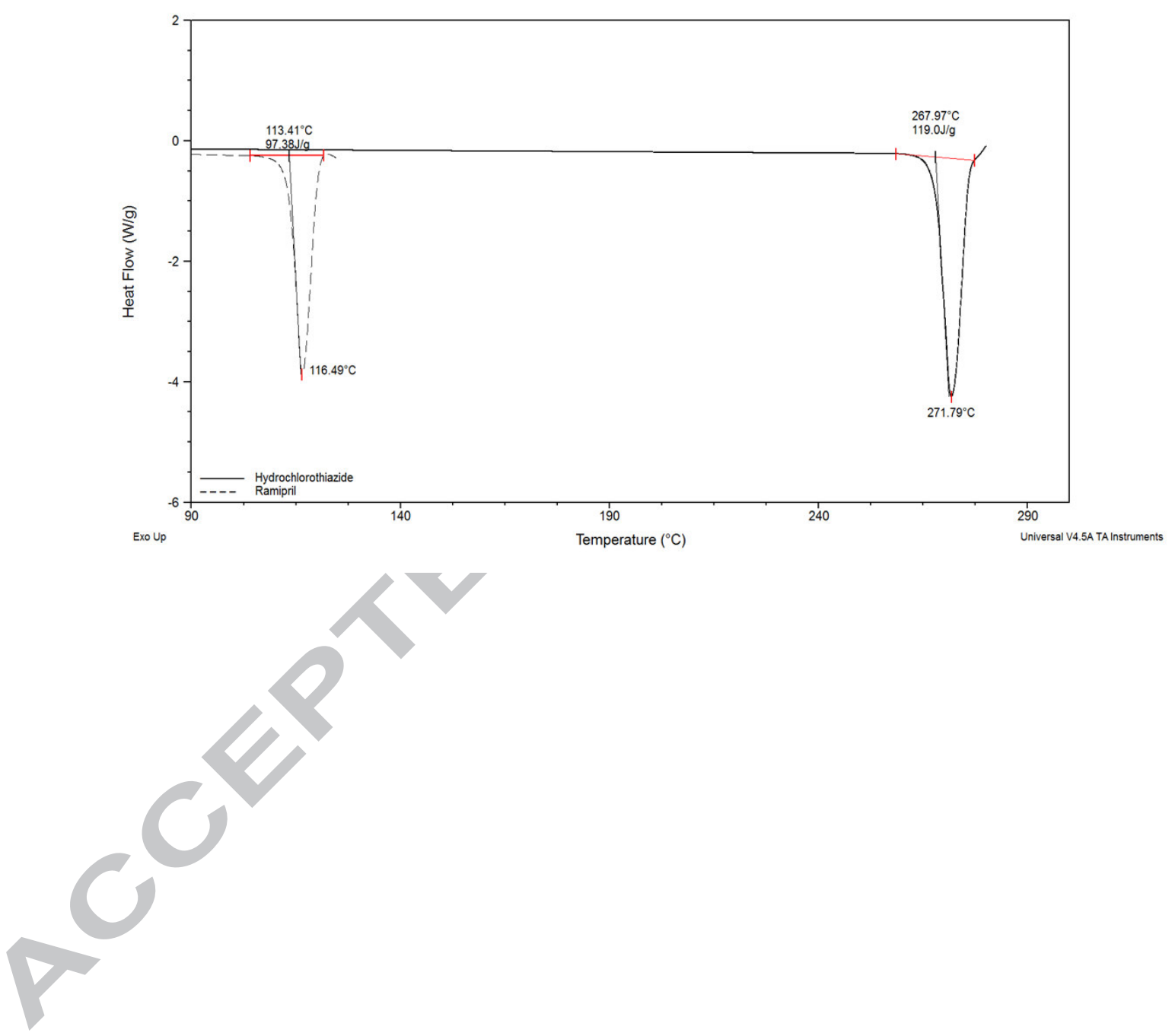
Figure 2.

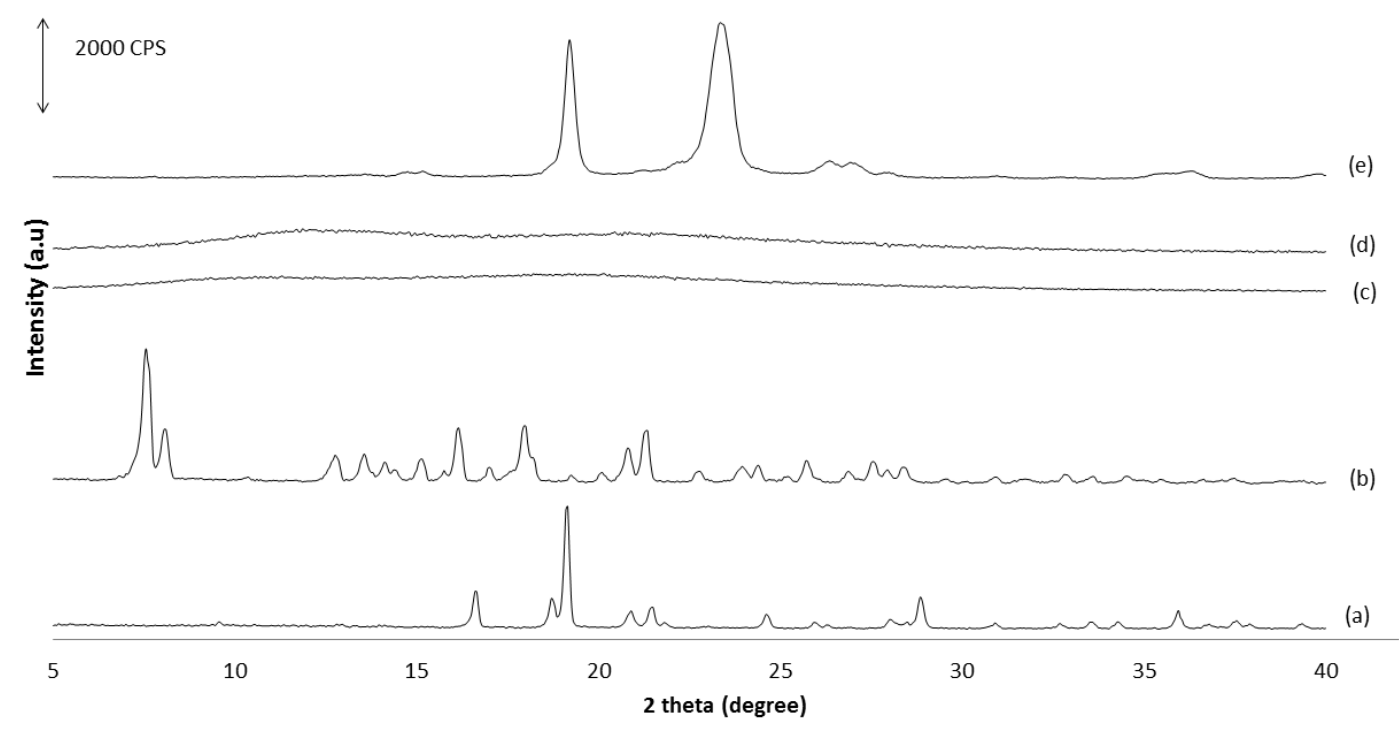


Figure 3.
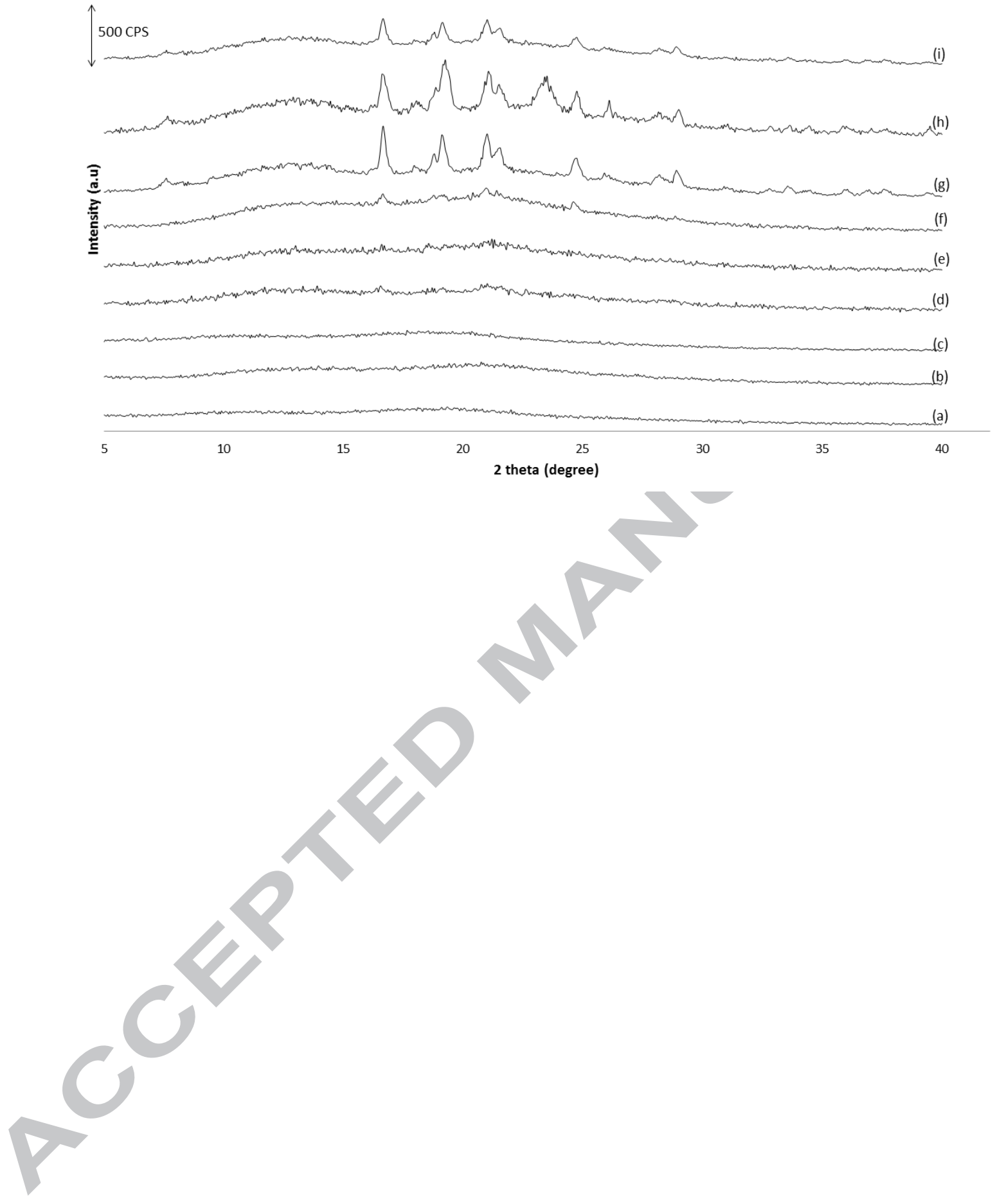


\section{ACCEPTED MANUSCRIPT}

Figure 4.

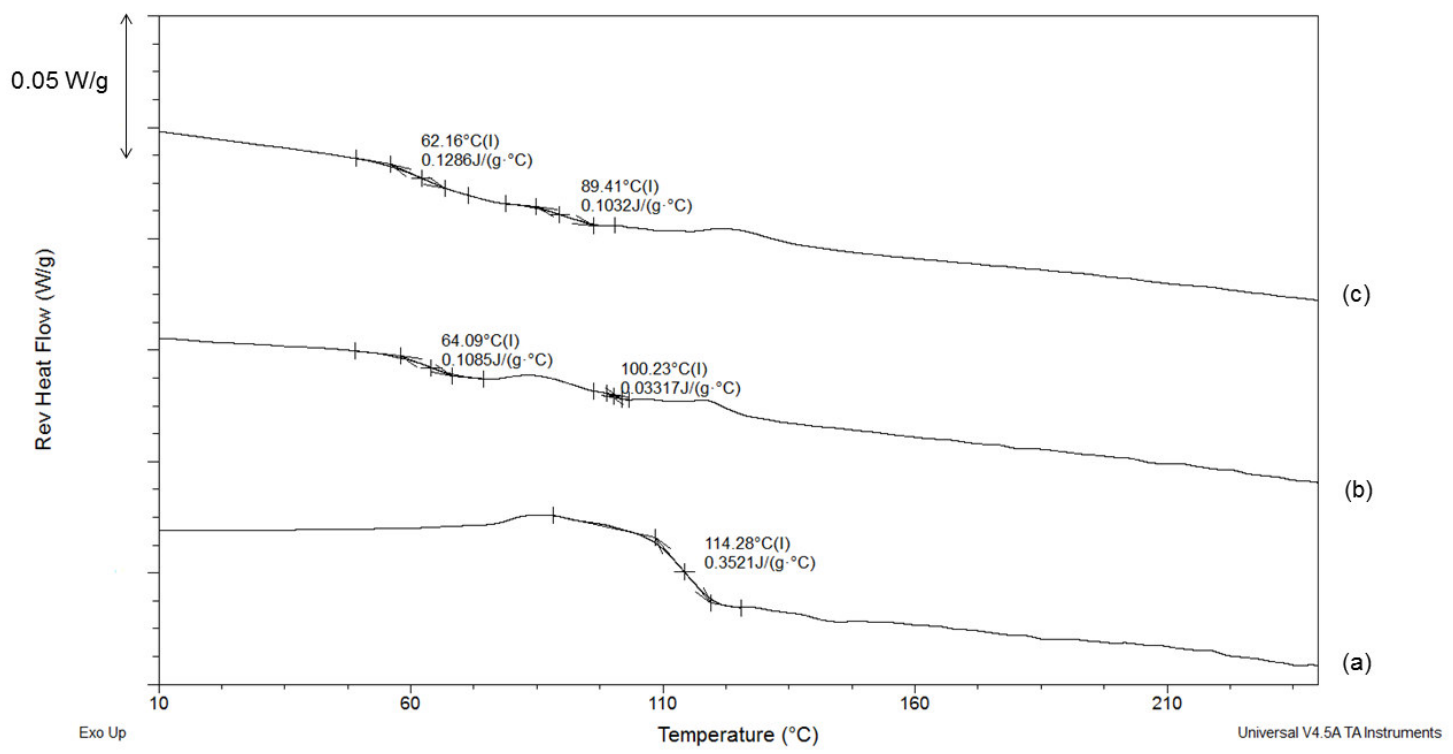




\section{ACCEPTED MANUSCRIPT}

Figure 5.

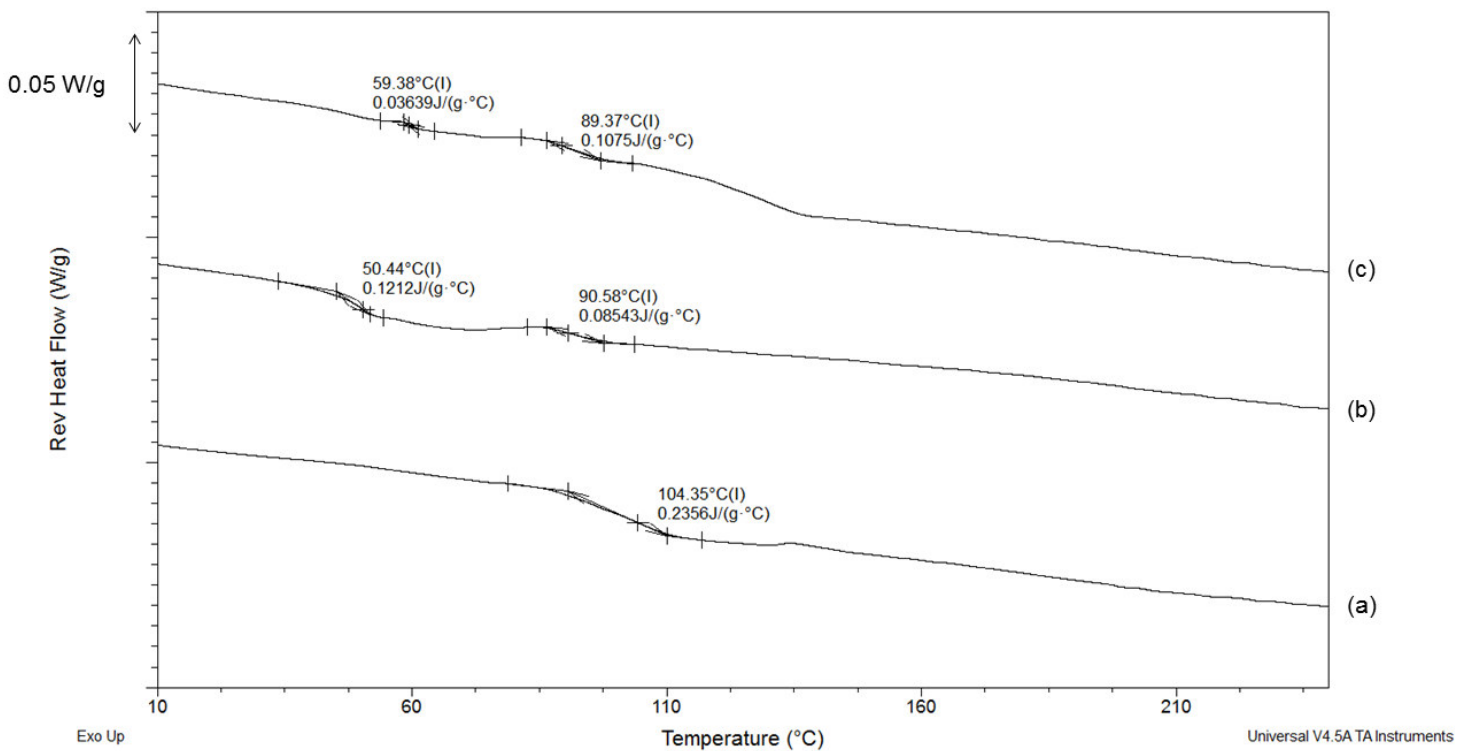


Figure 6.
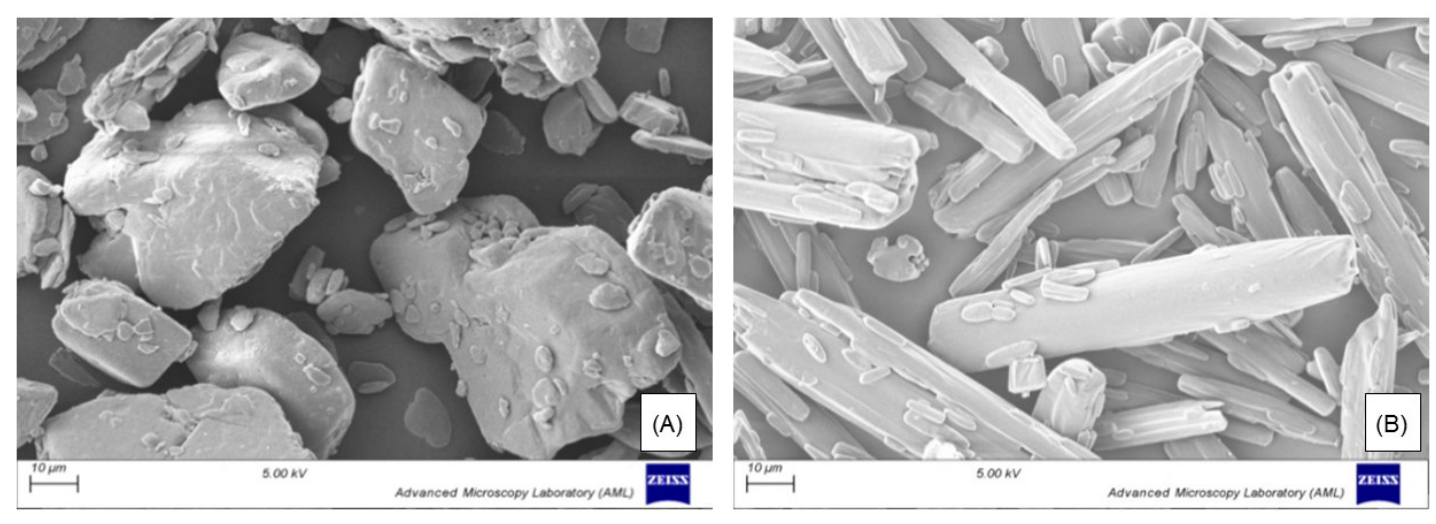
Figure 7.
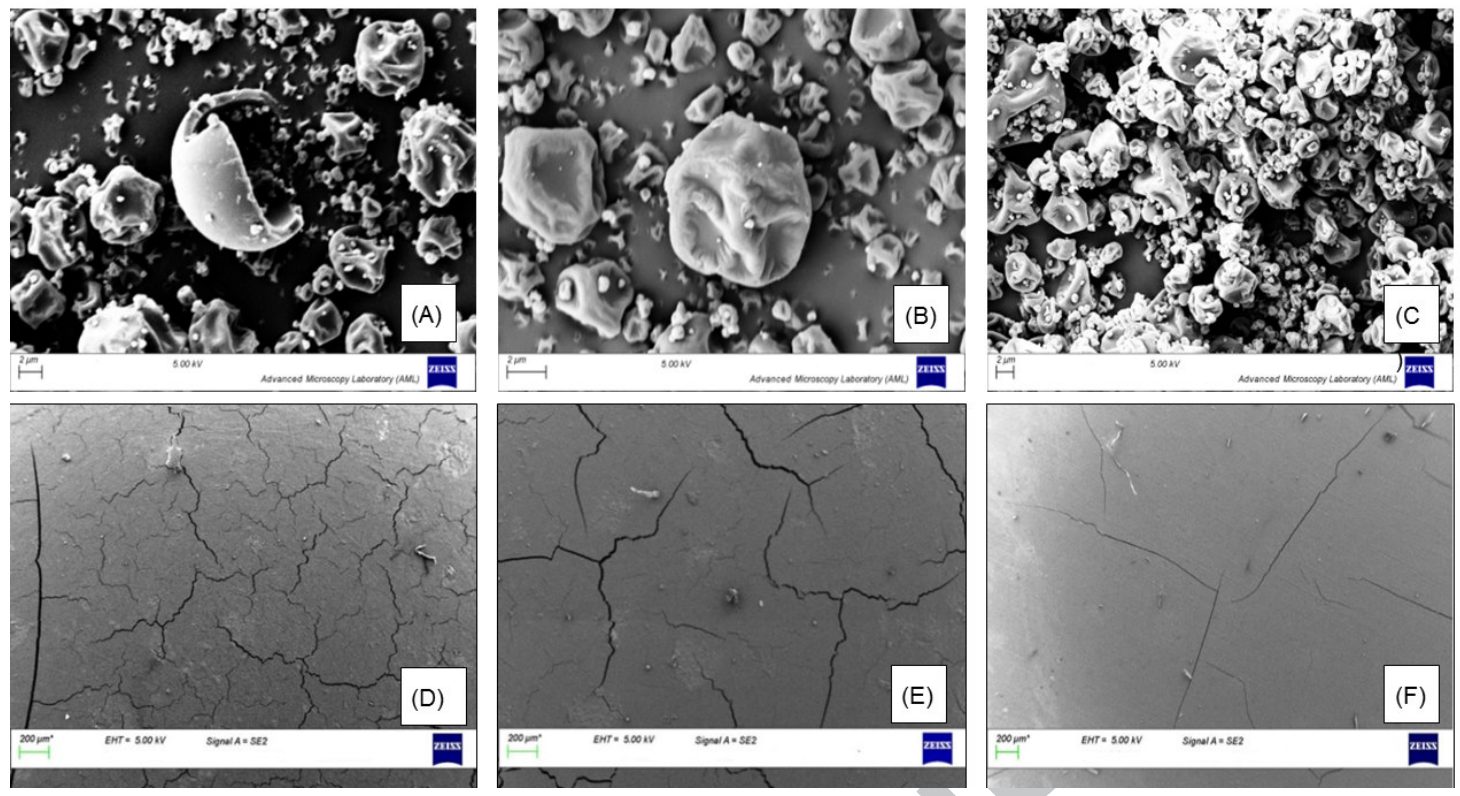
Figure 8.
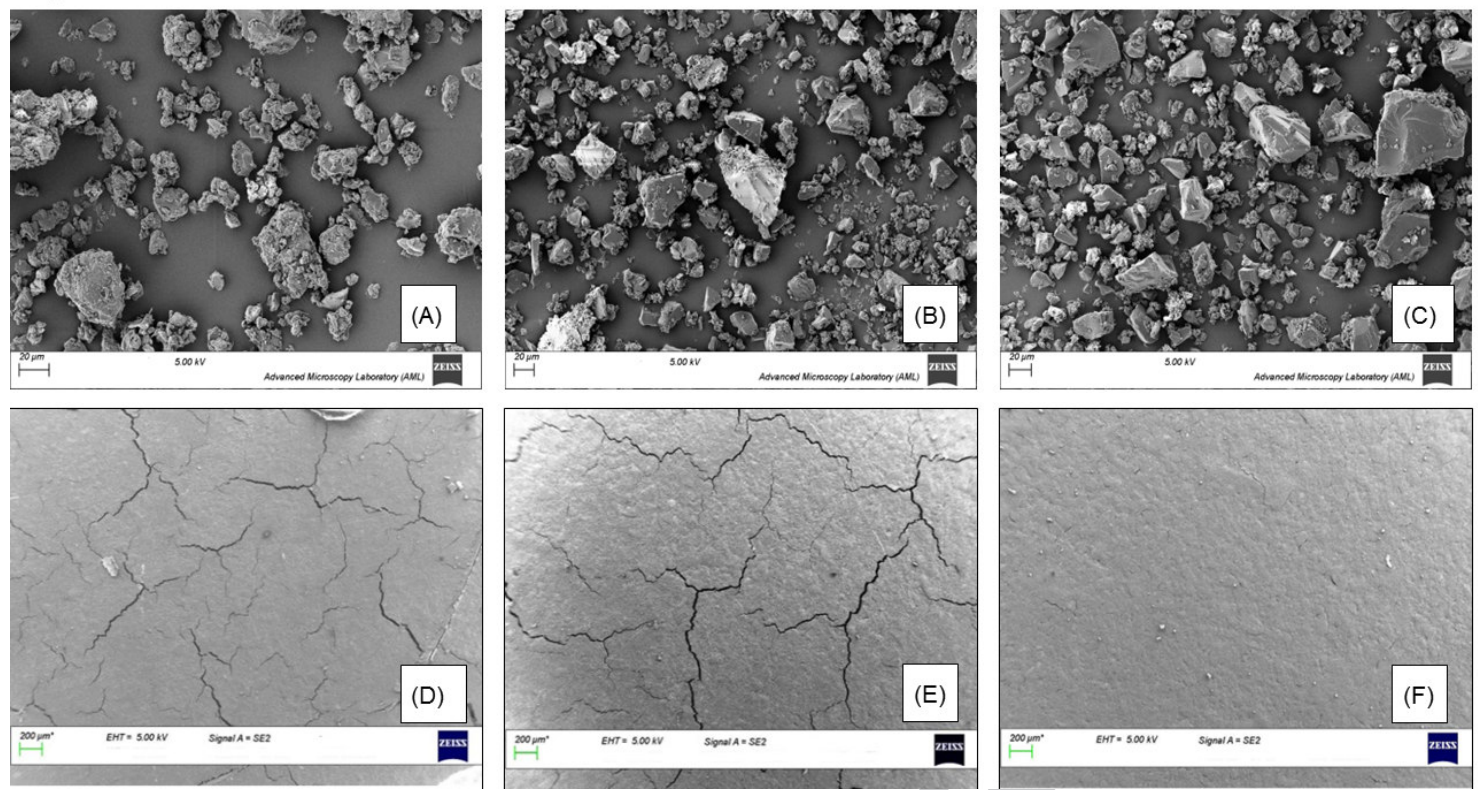
Figure 9.
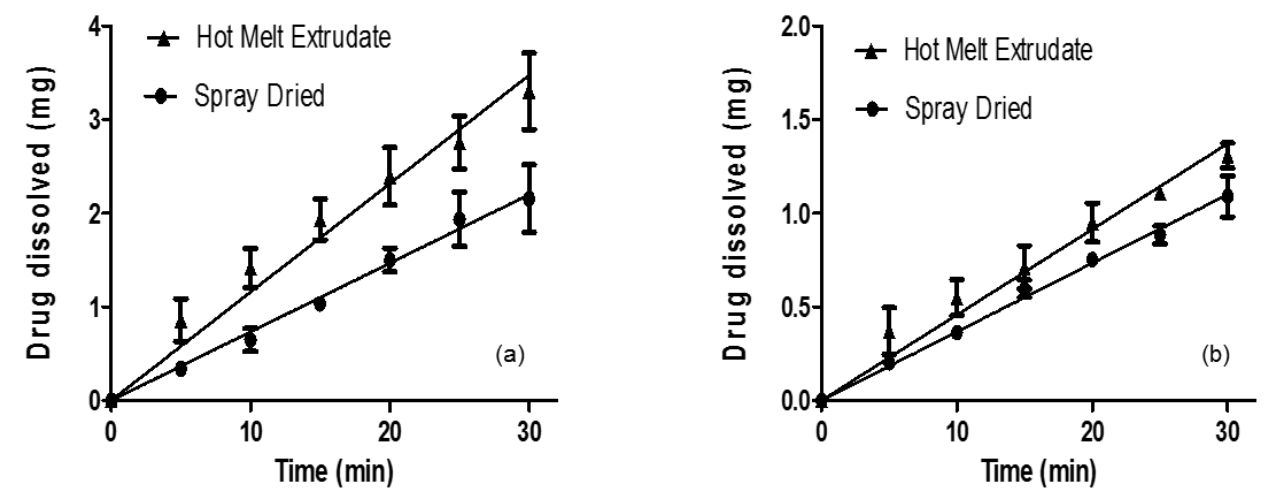
Figure 10.
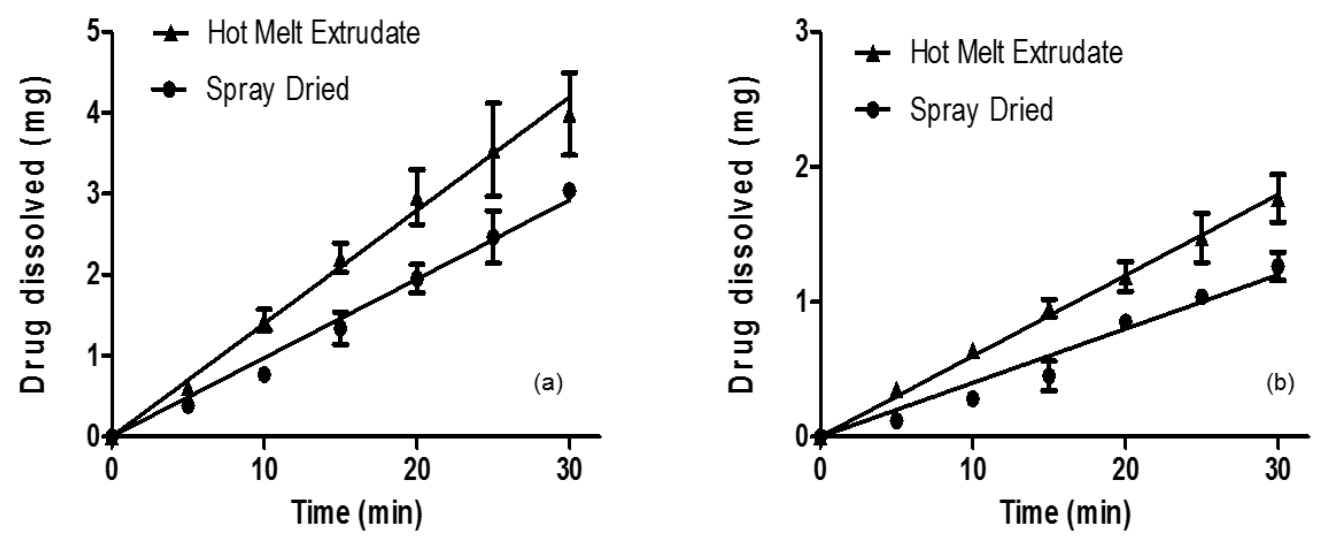


\section{ACCEPTED MANUSCRIPT}

Figure 11.
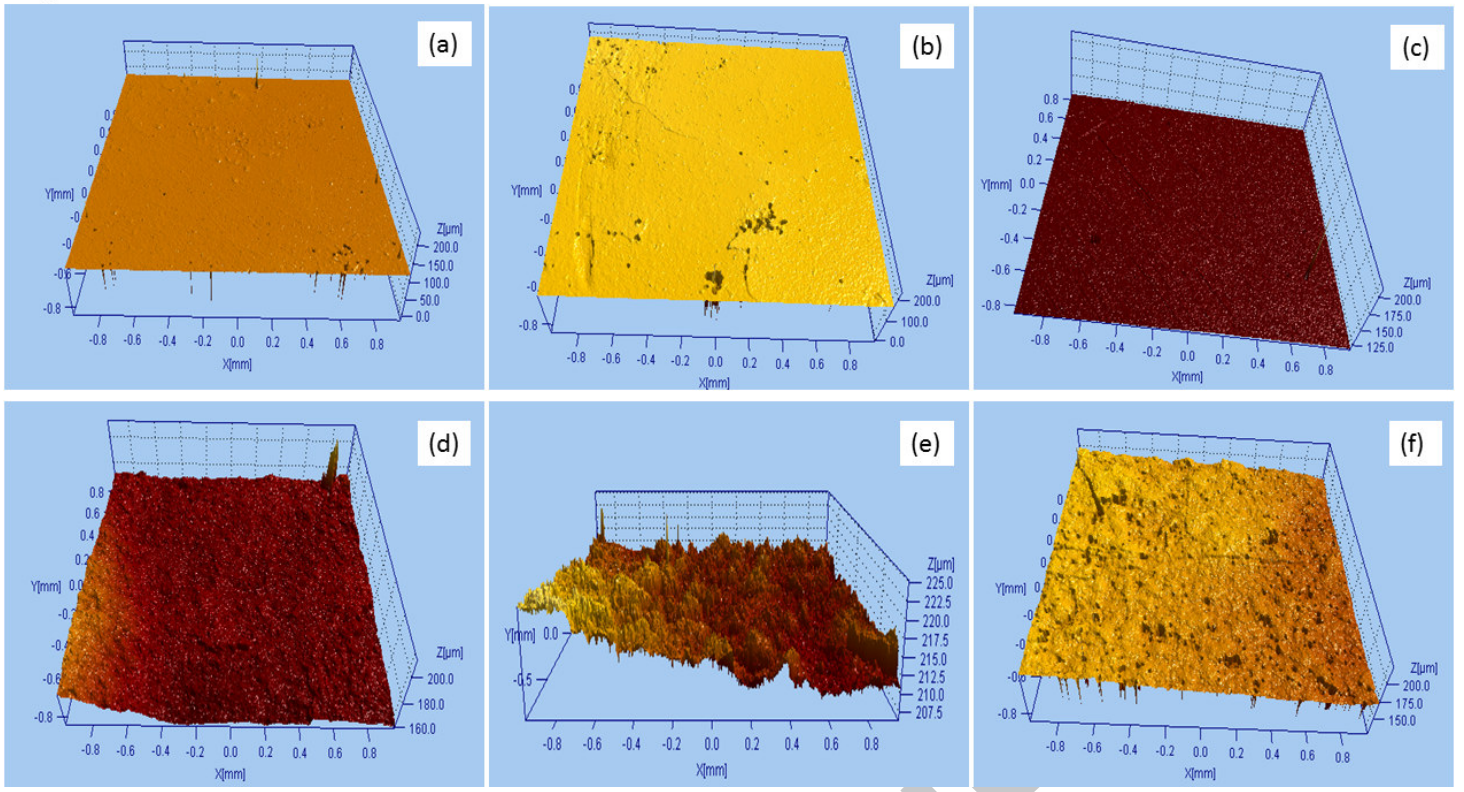


\section{List of Tables:}

A Comparative Study between Hot-Melt Extrusion and Spray-Drying for the Manufacture of Anti-Hypertension Compatible Monolithic Fixed-Dose Combination Products

J. F. Kelleher ${ }^{1}$, G. C. Gilvary ${ }^{2}$, A. M. Madi ${ }^{1}$, D. S. Jones ${ }^{2}$, S. Li ${ }^{2}$, Y. Tian ${ }^{2}$, A. Almajaan ${ }^{2}$,

Z. Senta-Loys ${ }^{2}$, G. P. Andrews ${ }^{2}$, A. M. Healy ${ }^{1}{ }^{*}$

Affiliation

${ }^{1}$ School of Pharmacy and Pharmaceutical Sciences, Trinity College Dublin, Dublin, Ireland

${ }^{2}$ School of Pharmacy, Queen's University of Belfast, Belfast, Northern Ireland

*To whom correspondence should be addressed to:

Anne Marie Healy

Tel: +35318961444

Email: healyam@tcd.ie

Table 1. Details of HPLC gradient elution method including time (min), mobile phase composition and flow rate $(\mathrm{ml} / \mathrm{min})(\%)$

\begin{tabular}{|l|l|l|l|}
\hline Time (min) & Mobile Phase A (\%) & $\begin{array}{l}\text { Mobile Phase B } \\
(\%)\end{array}$ & Flow (ml/min) \\
\hline 0 & 70 & 30 & 0.8 \\
\hline 5 & 40 & 60 & 1.5 \\
\hline 6 & 70 & 30 & 1 \\
\hline
\end{tabular}




\begin{tabular}{|l|l|l|l|}
\hline 9 & 70 & 30 & 1 \\
\hline 10 & 70 & 30 & 0.8 \\
\hline
\end{tabular}

Table 2. The composition of APIs and excipients in each of the formulations based on a $\%$ $w / w$

\begin{tabular}{|l|l|l|l|l|l|}
\hline & HCTZ & RAM & Kollidon VA & PEG 3350 & Soluplus \\
\hline Formulation 1 & $12.5 \%$ & $5 \%$ & $82.5 \%$ & $0 \%$ & $0 \%$ \\
(F1) & & & & & \\
\hline Formulation 2 & $12.5 \%$ & $5 \%$ & $74.25 \%$ & $8.25 \%$ & $0 \%$ \\
\hline Formulation 3 & $12.5 \%$ & $5 \%$ & $0 \%$ & $0 \%$ & $82.5 \%$ \\
\hline F3) & & & & & \\
\hline
\end{tabular}

Table 3. Processing conditions used during hot melt extrusion of pharmaceutical formulations.

\begin{tabular}{|l|l|l|l|l|l|l|l|}
\hline Formulation & Feed rate & Screw & Feed & Zone 1 & Zone 2 & Zone 3 & Die $\left({ }^{\circ} \mathrm{C}\right)$ \\
$(\mathrm{rpm})$ & speed & Zone & $\left({ }^{\circ} \mathrm{C}\right)$ & $\left({ }^{\circ} \mathrm{C}\right)$ & $\left({ }^{\circ} \mathrm{C}\right)$ & \\
\hline F1 & 10 & 20 & 90 & 110 & 140 & 140 & 120 \\
\hline F2 & 10 & 20 & 70 & 90 & 110 & 110 & 90 \\
\hline F3 & 10 & 20 & 90 & 110 & 140 & 140 & 120 \\
\hline
\end{tabular}


Table 4. Overview of particle size analysis (PSA) results of API raw materials and processed formulations

\begin{tabular}{|l|l|}
\hline Sample & $\begin{array}{l}\text { Particle Size }(\mu \mathrm{m}) \\
(\mathrm{d} 50)\end{array}$ \\
\hline HCTZ (Raw) & $28.48 \pm 0.13$ \\
\hline RAM (Raw) & $8.79 \pm 0.22$ \\
\hline HME-F1 & $50.48 \pm 2.45$ \\
\hline HME-F2 & $49.16 \pm 4.00$ \\
\hline HME-F3 & $36.16 \pm 0.74$ \\
\hline SD-F1 & $3.41 \pm 0.11$ \\
\hline SD-F2 & $3.00 \pm 0.02$ \\
\hline SD-F3 & $3.98 \pm 0.01$ \\
\hline
\end{tabular}

Table 5. Summary of drug content for processed formulations and intrinsic drug dissolution rates from compressed discs in $0.1 \mathrm{M} \mathrm{HCl} \mathrm{pH} 1.2 @ 37^{\circ} \mathrm{C}$ over 120 minutes

\begin{tabular}{|c|c|c|c|c|}
\hline Formulation & $\begin{array}{l}\text { HCTZ content } \\
(\%)\end{array}$ & $\begin{array}{l}\text { HCTZ dissolution } \\
\text { rate }\left(\mathrm{mg} / \mathrm{min} / \mathrm{cm}^{2}\right)\end{array}$ & $\begin{array}{l}\text { RAM content } \\
(\%)\end{array}$ & $\begin{array}{l}\text { RAM dissolution } \\
\text { rate }(\mathrm{mg} / \mathrm{min} / \\
\left.\mathrm{cm}^{2}\right)\end{array}$ \\
\hline HME-F1 & $101.44 \pm 1.45$ & $0.240 \pm 0.03$ & $90.71 \pm 0.65$ & $0.087 \pm 0.01$ \\
\hline HME-F2 & $101.88 \pm 2.10$ & $0.384 \pm 0.04$ & $96.07 \pm 0.01$ & $0.136 \pm 0.02$ \\
\hline HME-F3 & $99.64 \pm 0.46$ & N/A & $85.93 \pm 0.33$ & N/A \\
\hline SD-F1 & $100.69 \pm 0.57$ & $0.165 \pm 0.02$ & $99.54 \pm 0.20$ & $0.072 \pm 0.01$ \\
\hline SD-F2 & $100.33 \pm 0.74$ & $0.239 \pm 0.04$ & $101.89 \pm 1.25$ & $0.110 \pm 0.01$ \\
\hline
\end{tabular}




\begin{tabular}{|l|l|l|l|l|}
\hline SD-F3 & $101.25 \pm 1.64$ & N/A & $100.08 \pm 0.26$ & N/A \\
\hline
\end{tabular}

Table 6. Roughness average (Ra) of the surface of compressed discs for intrinsic dissolution

\begin{tabular}{|l|l|}
\hline Formulation & Roughness average (Ra) (nm) \\
\hline SD F1 & $121897 \pm 4857$ \\
\hline SD F2 & $171079 \pm 8641$ \\
\hline SD F3 & $148757 \pm 24077$ \\
\hline HME F1 & $171314 \pm 5350$ \\
\hline HME F2 & $215656 \pm 3188$ \\
\hline HME F3 & $174651 \pm 7573$ \\
\hline
\end{tabular}




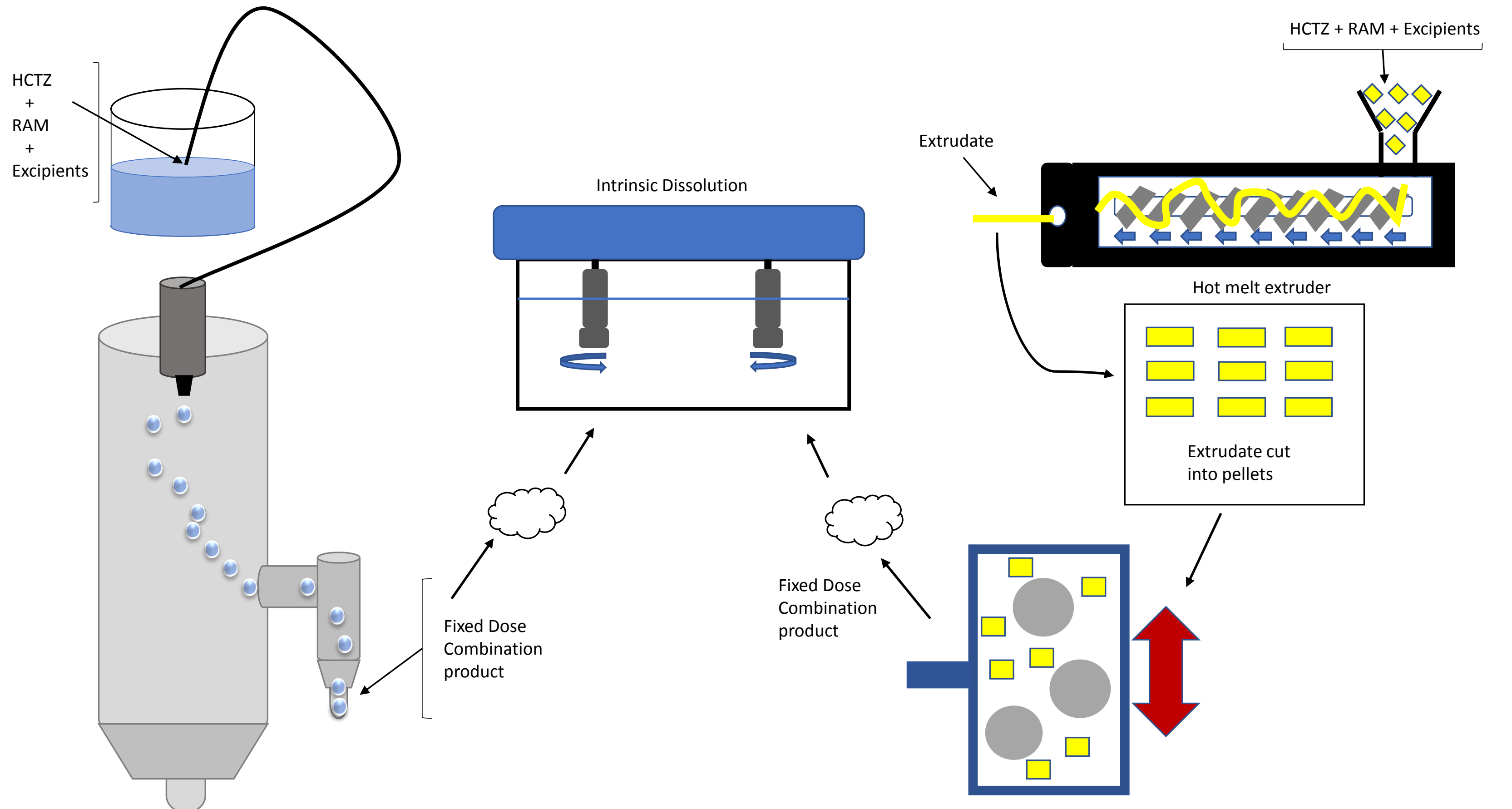

